\title{
THE FOX NEWS EFFECT: MEDIA BIAS AND VOTING*
}

\author{
Stefano DellaVigna and Ethan Kaplan
}

Does media bias affect voting? We analyze the entry of Fox News in cable markets and its impact on voting. Between October 1996 and November 2000, the conservative Fox News Channel was introduced in the cable programming of 20 percent of U. S. towns. Fox News availability in 2000 appears to be largely idiosyncratic, conditional on a set of controls. Using a data set of voting data for 9,256 towns, we investigate if Republicans gained vote share in towns where Fox News entered the cable market by the year 2000. We find a significant effect of the introduction of Fox News on the vote share in Presidential elections between 1996 and 2000. Republicans gained 0.4 to 0.7 percentage points in the towns that broadcast Fox News. Fox News also affected voter turnout and the Republican vote share in the Senate. Our estimates imply that Fox News convinced 3 to 28 percent of its viewers to vote Republican, depending on the audience measure. The Fox News effect could be a temporary learning effect for rational voters, or a permanent effect for nonrational voters subject to persuasion.

\section{INTRODUCTION}

Does the media affect voting behavior? According to rational expectation theories, voters filter out bias in reporting without being persuaded on average [Bray and Kreps 1987]. Alternatively, behavioral theories [De Marzo, Vayanos, and Zwiebel 2003] and cognitive linguistics theories [Lakoff 1987] suggest that voters are subject to media persuasion. Understanding the impact of the media is of interest not only for politics but also,

* George Akerlof, Stephen Ansolabehere, Lawrence M. Bartels, Robert Calo, Arindrajit Dube, Edward Glaeser, Matthew Gentzkow, Alan Gerber, Jay Hamilton, Lawrence Katz, Alan Krueger, Ulrike Malmendier, Marco Manacorda, Enrico Moretti, Suresh Naidu, Torsten Persson, Sam Popkin, Riccardo Puglisi, Matthew Rabin, Jesse Shapiro, Uri Simonsohn, Laura Stoker, David Stromberg, Daniel Sturm, and audiences at Beijing University, Bonn University (IZA), CarnegieMellon University, EUI (Florence), Fuqua, Harvard University (Economics Department and Business School), IIES (Stockholm), LSE, Princeton University, UC Berkeley, UC Davis, University of Chicago GSB, University of Munich (CES, Germany), University of Rochester, Uppsala University (Sweden), Wharton, and the NBER 2005 Political Economy and Labor Studies Meetings provided useful comments. We also thank the editor (Edward Glaeser) and three referees for detailed and helpful comments. We especially thank Jim Collins and Matthew Gentzkow for providing the Scarborough data. Shawn Bananzadeh, Jessica Chan, Marguerite Converse, Neil Dandavati, Tatyana Deryugina, Monica Deza, Dylan Fox, Melissa Galicia, Calvin Ho, Sudhamas Khanchanawong, Richard Kim, Martin Kohan, Vipul Kumar, Jonathan Leung, Clarice Li, Tze Yang Lim, Ming Mai, Sameer Parekh, Sharmini Radakrishnan, Rohan Relan, Chanda Singh, Matthew Stone, Nan Zhang, Sibo Zhao, and Liya Zhu helped collect the voting and the cable data. Dan Acland, Scott Baker, Thomas Barrios, Saurabh Bhargava, Avi Ebenstein, Devin Pope, Anitha Sivasankaran, and Justin Sydnor provided excellent research assistance.

() 2007 by the President and Fellows of Harvard College and the Massachusetts Institute of Technology.

The Quarterly Journal of Economics, August 2007 
more generally, for models of belief updating. From a policy perspective, if media bias alters voting behavior, deregulation of media markets may have a large impact on political outcomes.

In this paper, we address this question empirically. We exploit the natural experiment induced by the timing of the entry of the Fox News Channel in local cable markets and consider the impact on voting. The twenty-four-hour Fox News Channel ("Fox News" from here on) was introduced by Rupert Murdoch in October 1996. Fox News expanded rapidly to reach 20 percent of U.S. cities and an audience of 17.3 percent of the U. S. population by June 2000 (Scarborough Research data).

The decentralized nature of the cable industry induced substantial geographical variation in access to Fox News. Cable companies in neighboring towns adopted Fox News in different years, creating idiosyncratic differences in access. Since Fox News is significantly to the right of all the other mainstream television networks [Groseclose and Milyo 2005], the introduction of Fox News into a cable market is likely to have had a significant effect on the available political information in that cable market. This is true whether Fox News represents the political center and the rest of the media the liberal wing, or Fox News represents the right and the rest of the media the middle.

To analyze whether the change in political information affects voting, we assemble a new panel of town-level data on federal elections and match it with town-level data on cable programming. We compare the change in the Republican vote share between 1996 and 2000 for the towns that had adopted Fox News by 2000 with those that had not. Conditional on a set of geographic and cable controls, the availability of Fox News is uncorrelated with town-level demographic controls and with town-level voting patterns in 1996 and before 1996.

Our main result is that Fox News had a significant impact on the 2000 elections. The entry of Fox News increased the Republican vote share in presidential elections by 0.4 to 0.7 percentage points, depending on the specification. Since Fox News in 2000 was available in about 35 percent of households, the impact of Fox News is estimated to be 0.15 to 0.2 percentage points, 200,000 votes nationwide. While this vote shift is small compared to the 3.5 percentage point shift overall in our sample between 1996 and 2000 , it is still likely to have been decisive in the close presidential elections.

We check our identification strategy with placebo specifica- 
tions; in particular, we show that availability of Fox News in 2000 did not affect the vote share between 1992 and 1996 or between 1988 and 1992, when Fox News did not yet exist.

We provide evidence that the Fox News effect varies with town characteristics. The effect was smaller in towns with more cable channels, which is consistent with a moderating effect of competition [Mullainathan and Shleifer 2005]. In addition, Fox News had a smaller effect in rural areas and in Republican congressional districts, possibly because in these towns the share of non-Republicans at risk of being convinced was smaller.

We also analyze whether Fox News affected voting in races where Fox News did not cover the candidates directly, as in most Senate races. This allows us to estimate whether the influence of Fox News is candidate-specific or whether it extends to general political beliefs. We find that Fox News significantly increased the Republican vote share for the Senate by 0.7 percentage points. Additionally, the effect is not significantly larger for the one Senatorial race that Fox News covered heavily, the New York State race between Hillary Clinton and Rick Lazio. Fox News appears to have induced a generalized ideological shift.

Finally, we consider whether the Fox News effect on presidential elections was mainly a result of voters switching party lines or of additional voter turnout to the polls. We find that Fox News significantly increased voter turnout, particularly in the more Democratic districts. The impact of Fox News on voting appears to be due, at least in part, to the mobilization of voters and particularly conservative voters in Democratic-leaning districts.

Overall, we find a sizeable impact of Fox News on the vote share for Republicans. To quantify the persuasion rate of the media, we incorporate information on the extent of viewership and the share of Republicans in the Fox News audience. Using two different audience measures from Scarborough Research data, we compute the impact on the Fox News viewership of availability of Fox News in local cable programming. The more inclusive audience estimates imply that Fox News convinced between 3 and 8 percent of its non-Republican viewers to vote Republican, depending on the specification. The more restrictive audience measures imply persuasion effects between 11 and 28 percent. Exposure to more conservative coverage, therefore, had a sizeable, and possibly large, persuasion effect.

We compare the persuasion rates estimated in our study with 
the persuasion rates implied by other studies of media effects on political beliefs or voting. ${ }^{1}$ These studies include field experiments on voter turnout [Green and Gerber 2004] and on party choice [Gerber, Karlan, and Bergan 2006], laboratory experiments involving exposure to political advertisements [Ansolabehere and Iyengar 1995], and poll studies [Kull, Ramsey, and Lewis 2003; Gentzkow and Shapiro 2004]. Our estimates of persuasion rates are in the range of most estimates in the literature.

We consider three explanations of our results. The first explanation is that the findings are spurious and are induced by entry of Fox News in towns that were independently becoming more conservative. Contrary to this explanation, these towns were no more conservative, nor were they becoming more conservative before the entry of Fox News. A second explanation is based on rational learning. To the extent that voters are initially uncertain about the bias of Fox News, exposure will have a (temporary) effect on beliefs and voting. Voters attribute the positive coverage of George W. Bush in 2000 partly to Republican bias of the media source (Fox News) but partly also to high quality of the Republican candidate (Bush). By the year 2000, however, the conservative slant of Fox News should have been clear. This explanation also makes the prediction that the media effect should disappear over time, contrary to the evidence that the Fox News effect does not decrease between 2000 and 2004. A third explanation is that viewers do not sufficiently account for media bias and are subject to nonrational persuasion. In this case, exposure to media slant systematically alters beliefs and voting behavior. In the working paper version [DellaVigna and Kaplan 2006] we model the latter two explanations.

The latter interpretation relates to behavioral literature on nonrational persuasion [DeMarzo, Vayanos, and Zwiebel 2003]. Cain, Loewenstein, and Moore [2005] show in an experiment that evaluators of information do not take sufficiently into account the (known) incentives of the advisors and are thus persuaded by their advice. Malmendier and Shanthikumar [forthcoming] show that small investors follow the recommendations of affiliated analysts, despite the conflict of interest of the analysts.

Our paper contributes to the evidence on the impact of media

1. Dyck and Zingales [2003] and Huberman and Regev [2001], among others, find that media coverage has a large impact on stock returns, even when arguably it conveys no new information. 
market expansions on voter turnout. Expansions of The New York Times in the 1990s [George and Waldfogel 2006], of television between 1940 and 1972 [Gentzkow 2006], and of cable in the 1970s [Prior 2006] decrease turnout, while radio entry between 1920 and 1940 increases turnout [Stromberg 2004]. Unlike in these studies, we examine the introduction of a politically slanted media and estimate the effect of media persuasion.

The paper also adds to the empirical literature on media bias [Herman and Chomsky 1998; Hamilton 2004; Puglisi 2004; Groseclose and Milyo 2005] and the theoretical literature on it [Mullainathan and Shleifer 2005; Gentzkow and Shapiro 2006]. We provide evidence that exposure to media bias persuades voters, an implicit assumption underlying most of these papers.

The remainder of the paper is structured as follows. In Section II we provide background information on Fox News and we describe the data. In Section III we present the empirical results, including a comparison to results from an earlier draft of this paper in which we found no effect of Fox News. In Section IV we present estimates of persuasion rates and interpretations, and in Section V we conclude.

\section{Fox News History and Data}

Fox News History and Content. In March of 1996, Rupert Murdoch announced the introduction of a twenty-four-hour-aday cable news channel, Fox News. Prior to the launch of Fox News, news broadcasts took up a small share of programming of the Fox Broadcasting Corporation, which included channels like Fox Entertainment and the Fox Family Channel. There was no national news broadcast, and prime time programming on the Fox channels did not include news.

The political coverage of Fox News is to the right of the coverage of the other main television news sources, the major networks-ABC, CBS, and NCB-and CNN. Groseclose and Milyo [2005], for example, compute an index of political orientation of news programs using citations of think tanks. They estimate that Fox News Special Report is significantly to the right of the other mainstream television media (ABC, CBS, CNN, and NBC). The news coverage of Fox News is also estimated to be to the right of the average U. S. elected official.

The distribution of Fox News started on October 7, 1996, in a 
limited number of cable markets. The cable industry is a local natural monopoly due to the fixed cost of laying cables. In our sample, only 10 percent of towns have two or more cable companies. In addition, cable companies face a technological constraint on the number of channels. News channels like Fox News have to convince local cable companies to be added, often at the expense of other channels. The timing of the agreement between Fox News and the cable companies is one factor inducing idiosyncratic diffusion of Fox News. TCI was one of the first companies to sign an agreement. By November 2000, AT\&T Broadband, which acquired TCI Cable in 1999, offered Fox News in 32.5 percent of the 1,955 towns served by its affiliates (in our sample of twenty-eight U. S. states). Adelphia Communications, which had a late agreement with Fox News, offered Fox News in only 7.5 percent of the 1,592 towns in our sample served by its affiliates.

In addition to the twenty-four-hour cable programming, Fox News distributes short news segments to local TV stations that are affiliates of Fox Broadcasting. However, the twenty-four-hour channel is only available via cable and to twelve million satellite subscribers (in 2000). ${ }^{2}$

By the year 2000, Fox News was present in 20 percent of towns in our sample with cable service. Since the towns reached by Fox News in 2000 were more than twice as large as the remaining towns, Fox News was available to 34.3 percent of the population of these states.

Fox News Audience. We document the Fox News penetration and the composition of the Fox News audience using microlevel data from Scarborough Research. Scarborough uses a representative panel of households to collect demographic variables and two audience measures for each TV channel surveyed. The first and more inclusive audience measure, the recall measure, is the share of respondents who answer yes to the question on whether they watched a given channel in the past seven days. The second and more restrictive measure, the diary measure, is tabulated from a week-long diary of TV watching and is the share of respondents who watched a channel for at least one full half-anhour block according to the seven-day diary.

2. As of June $2000,14,458,000$ U. S. households subscribed to a satellite service, but two million of these subscribers did not receive Fox News (Satellite Broadcasting and Communications Association, from http://www.sbca.com/ index.asp). 
In column (1) of Table I, we report summary statistics for the 105,201 respondents to the August 2000-March 2001 survey. The recall audience for Fox News is 17.3 percent, and 34.1 percent for CNN. According to this measure, by the year 2000, Fox News already had an audience half as large as that of CNN. The diary audience is not available for this sample. We also present summary statistics for the Fox News audience (column (2)) and for the rest of the sample (column (3)). The education level and unemployment rate are comparable across the two samples, African Americans are somewhat more likely to listen regularly to Fox News, and Hispanics somewhat less likely. The Fox News audience is older and more likely to be male.

Turning to the political variables, 37.5 percent of the Fox News recall audience self-identify as Republican, 29.4 percent as Democrat, and the remainder as Independent. Among the nonFox News audience, 26.2 percent identify as Republican and 32.4 percent as Democrat. Fox News viewers therefore are more likely to be Republican. ${ }^{3}$ Since the audience data are from 2000, after the entry of Fox News, this difference could be due either to sorting to Republicans into the Fox News audience or to a persuasion effect of exposure to Fox News. Self-reported turnout to Presidential elections is higher in the Fox News audience.

In columns (4)-(6), we focus on the subsample for which zip code of residence and the diary audience measure are both available. This sample was recorded between February 2000 and August 2001 in five geographical areas. ${ }^{4}$ We further restrict the sample to the 11,388 respondents living in one of the 568 towns with available cable and election data. In Section IV.A, we use this subsample to estimate the impact of Fox News availability via cable on the Fox News audience. This sample (column (4)) is similar to the whole sample (column (1)) both with respect to the measure of the Fox News recall audience and with respect to demographics, except for a higher share of Hispanic viewers. The diary audience is three to five times smaller than the corresponding recall audience: 0.035 for Fox News (recall audience 0.166) and 0.103 for CNN (recall audience 0.353). The diary audience measure is less inclusive than the recall

3. We find a similar pattern for audience measures of CNN and CNBC, suggesting that the selection of Republicans into the Fox News audience may simply reflect selection of Republicans into news channels.

4. The data include respondents residing in the Designated Market Areas (DMAs) of Chicago (September 2000-August 2001), Los Angeles (February 2000 January 2001), Pittsburgh (September 2000-August 2001), New York (March 2000-February 2001), and Washington, D.C. (March 2000-February 2001). 


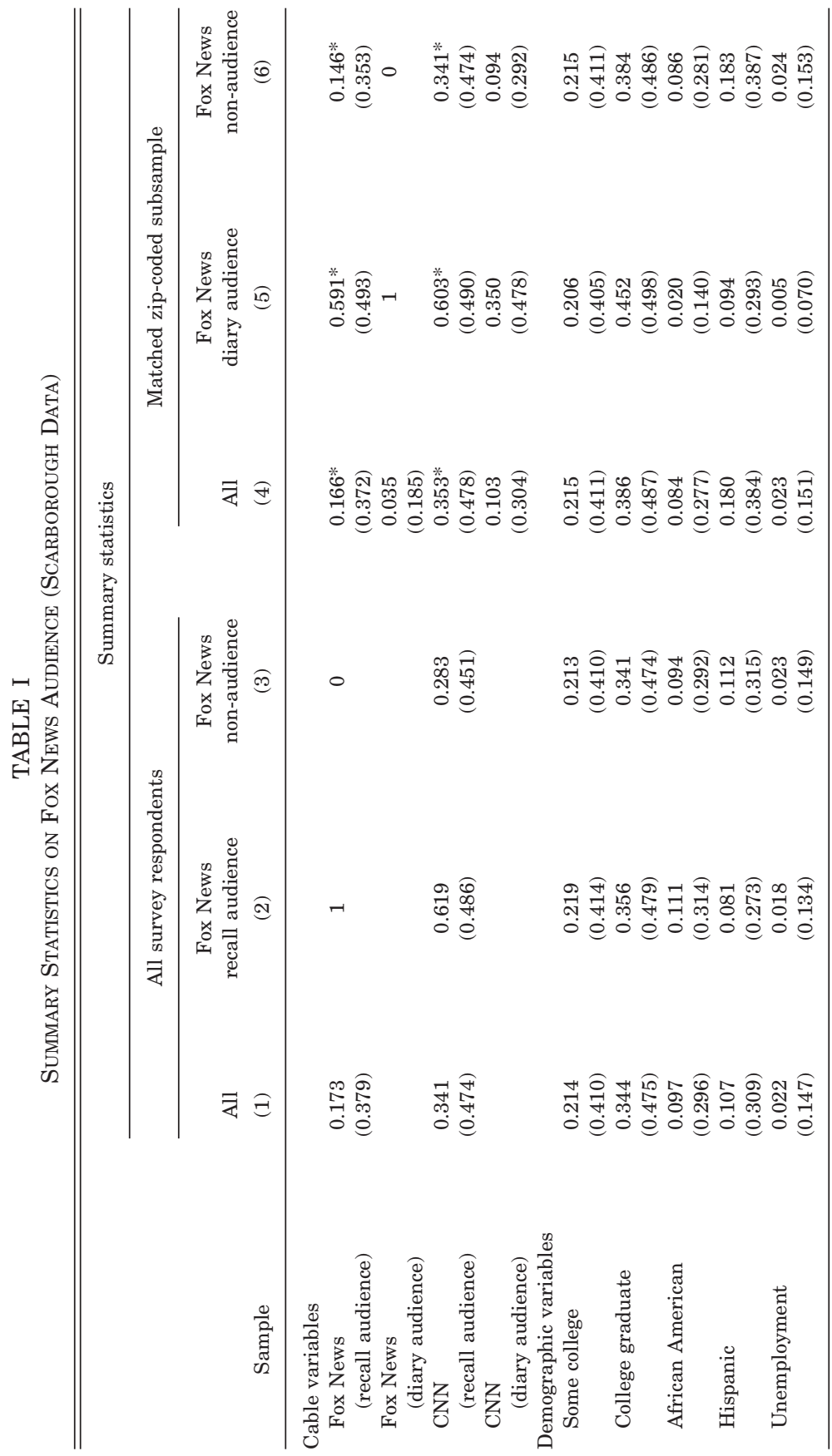




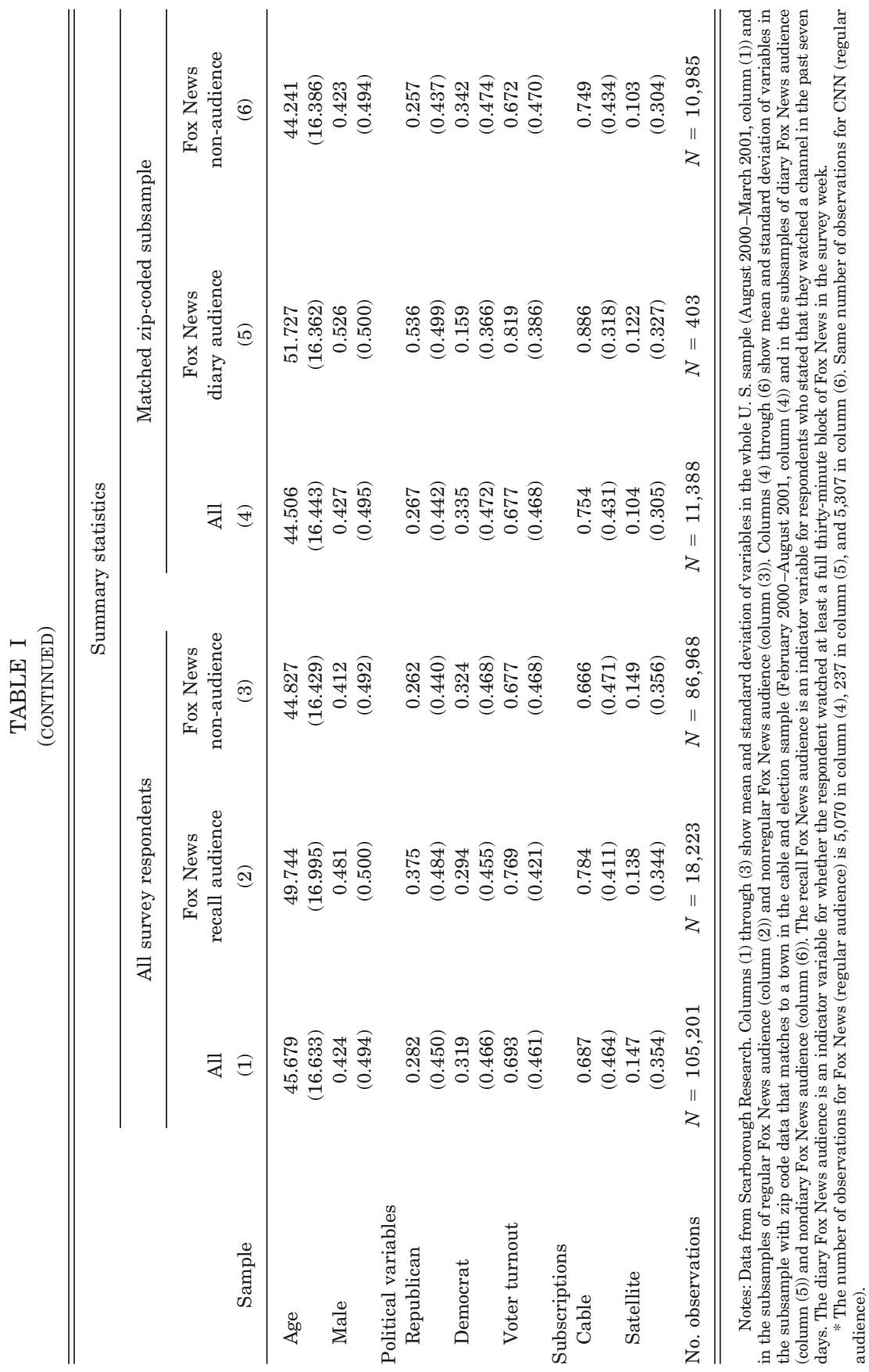


measure, since it excludes anyone who, in the previous week, watched a channel for less than a full half hour block (a likely pattern for a news channel). It is also less subject to memory biases, which may lead to over-reporting of the recall audience. Throughout the paper, we report the results with both measures.

In columns (5) and (6) we compare the Fox News audience and the non-Fox News audience according to the diary measure. The differences between these two samples resemble the ones found according to the recall audience measures (columns (2) and (3)), except that political differences are more accentuated and that African Americans are less likely to watch Fox News according to the diary measure.

Data. The data on local cable companies are from a paper copy of the Television and Cable Factbook, 2001 edition [Warren 2001]. This edition contains information as of November 2000, that is, right up to the 2000 elections. We did not collect information for the year 1996 since Fox News became available only in October 1996 and just for a limited number of markets. In the Appendix we present details on this data.

The main source of election data was the Election Division of the Secretary of State of each state. Other sources are the Federal Election Project [Lublin and Voss 2001] for the year 2000, the Record of American Democracy (ROAD) Project [King et al. 1997] for the year 1988, and the Atlas Election data [Leip 2004] for the 2004 presidential election.

We aggregate the voting information to the town level. A first group of states-California, New Jersey, New York, and the New England States-directly provide voting information at the town level, which we employ. A second group of states-Iowa, Minnesota, Michigan, Montana, Ohio, Pennsylvania, Wisconsin, and Wyoming-provide precinct-level voting information with corresponding town name, which we use to aggregate to the town level. A third group of states-Alaska, Alabama, Arkansas, Hawaii, Idaho, Missouri, North Dakota, South Carolina, Tennessee, Utah, and Virginia - only have precinct-level voting information, with precinct names that usually include the name of the town but sometimes do not. Examples of precinct names are "02-Concord Elem School" and "Hot Springs Retirement Hm." For these states, we recover the town name from the precinct name by elimination of numbers and commonly used words, such as "School" and 
"Retirement Hm." ${ }^{5}$ We then aggregate the voting data over precincts with the same town name in a given county and state. The twenty-eight U. S. states that have voting information that we can aggregate to the town level for both years 1996 and 2000 form the sample used in this paper. The aggregation procedure generates 26,710 distinct localities.

For the twenty-eight U.S. states in our sample, we collect demographics from the 2000 and the 1990 Census at the level of "Place," including "Remainders of Place." We transform the place name and aggregate the Census data using the same code employed for the election and cable data. This procedure leaves 27,064 towns with information from both the 2000 and the 1990 Census.

We match the cable, the election, and the Census data by the state, county, and town name, yielding 10,126 localities. We drop 289 towns with multiple cable systems, at least one of which carries Fox News and at least one of which does not. For these towns, we do not know if cable consumers have access to Fox News. Additionally, we drop 324 towns with cable systems that do not offer CNN as part of the cable package. In these towns, cable offerings are typically limited to the reprogramming of local cable channels. Their news programming, therefore, is not comparable to the programming of the other towns. ${ }^{6}$ Finally, we drop 257 towns with likely voting data problems: 238 towns for which the number of precincts generating the town-level vote count differs by more than 20 percent between 1996 and $2000 ;{ }^{7}$ and nineteen towns for which the total number of votes cast in the presidential election differs by more than 100 percent between 1996 and 2000 . For these observations, the problems are likely due to imperfect matching of the precincts aggregated to the town level in 1996 and 2000 .

The final sample of 9,256 towns has comparable Fox News availability relative to the initial sample and somewhat lower Republican vote share in 2000 and 1996 because the unmatched towns are more likely to be small and rural. The final sample

5. The Stata ado file that translates precinct names into town names is available upon request.

6 . The results do not vary if we include these towns.

7. We do not apply this criterion for Michigan, New Hampshire, New York, Ohio, Rhode Island, and Utah since the numbering of precincts is not comparable across 1996 and 2000. 


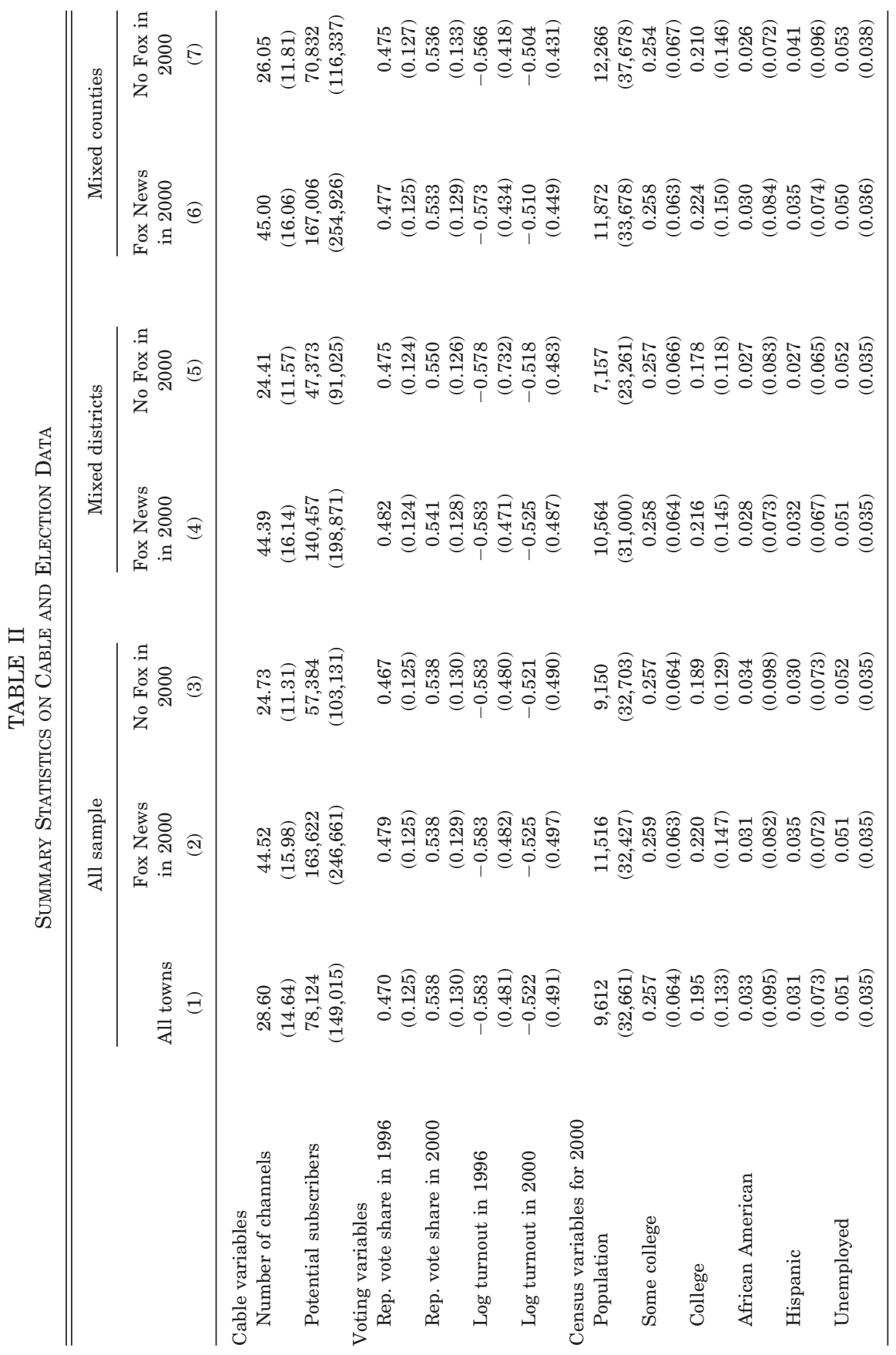




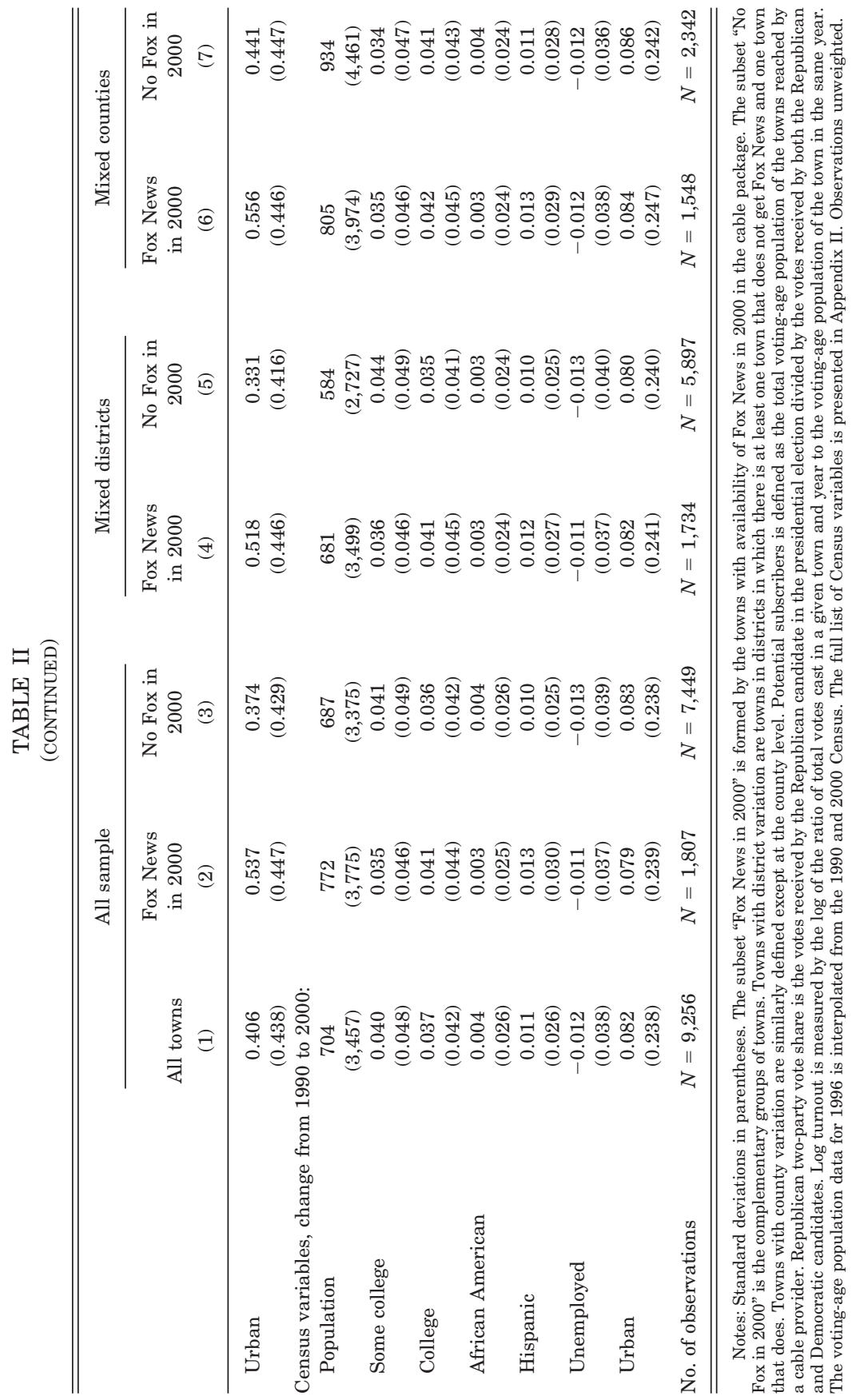


covers 65.9 percent of the population and 68.6 percent of total votes cast for the twenty-eight states in the year $2000 .^{8}$

Summary Statistics. Table II presents unweighted summary statistics on the cable and election data. The average cable system in the year 2000 included twenty-eight channels in the Basic and Expanded Basic programming and reached a population of 78,124 . The mean town population was 9,612 with a median of 2,766 . As Census controls, we include the share of the population with some college, the share of college graduates, the share of African Americans and of Hispanics, the unemployment rate, and the share of the town that is urban (shown in Table II). We also include the share of high school graduates, the share of males, the marriage rate, the employment rate, and average income (not shown in Table II).

We compare towns that offered Fox News in their programming (column (2)) and towns that did not (column (3)). Towns that offer Fox News have a substantially higher number of channels offered (44.5 versus 24.7), are 25 percent larger, are served by cable companies that reach three times as many people, and are more likely to be urban.

More importantly, towns that offered Fox News by 2000 increased their Republican vote share by 5.9 percentage points (from 47.9 to 53.8 percent) between 1996 and 2000, while those that did not offer Fox News increased theirs by an even larger 7.1 percentage points (from 46.7 to 53.8 percent). These figures suggest a perverse Fox News effect. This result, however, does not weight towns by size, nor does it take into account differences between Fox and non-Fox towns in voting trends across geographical areas, demographic composition, and cable market. Later, we estimate the Fox News effect, taking into account all these factors.

The overall sample spans 235 congressional districts, out of 435 total. Out of these 235 districts, 152 districts include both

8. The coverage rate is lower than 100 percent for three reasons: (i) we drop some of the largest cities like New York, which have several cable systems, some of which carry Fox News, and some of which do not; (ii) in states like Missouri, some counties have numeric precinct names that we cannot match to a town; and (iii) in states like Arkansas, complicated precinct names induce a poor match between the election data and the cable and Census data. The exclusion of large cities or certain counties or precincts should not affect the results, as long as Fox News availability and the election outcomes are measured correctly for the matching towns. Details on the state-by-state coverage rate is in Appendix Table I in DellaVigna and Kaplan [2006]. 
towns that offered Fox News and towns that did not. In our difference-in-difference specification with district fixed effects, the effect of Fox News is estimated on the 7,631 towns in this subsample. Towns in this subsample (columns (4) and (5) of Table II) are smaller but otherwise comparable to the overall sample.

We also consider the distribution of Fox News at the finer geographical level of the county. Only 284 counties out of 1,156 incorporate both towns with Fox News and towns without (Figure I). In our specification with county fixed effects, the effect of Fox News is estimated on the 3,890 towns in these counties. Towns with Fox News (column (6) of Table II) and without Fox News (column (7)) in this subsample are close geographical neighbors and, therefore, more closely matched on observables.

\section{EMPIRICAL ReSUlts}

\section{III.A. Selection}

In this paper, we compare towns with Fox News in their programming in the year 2000 to towns without Fox News. Since the assignment of towns into these two groups is not random, we investigate the nature of the selection and estimate which townlevel variables predict the availability of Fox News in 2000. In particular, we focus on political variables. Fox News may well have expanded first in Republican areas since demand for its services is likely to be higher in these areas. If Republican areas were becoming more Republican between 1996 and 2000, the estimated Fox News effect may just be capturing political trends.

The Fox News variable, $d_{k, 2000}^{\mathrm{FOX}}$, equals one if all cable systems in town $k$ in year 2000 include Fox News in either the Basic package or one of the Expanded Basic packages, and zero if no cable system includes Fox News. We estimate a linear probability model $^{9}$ :

$$
\begin{aligned}
d_{k, 2000}^{\mathrm{FoX}}=\alpha+\beta v_{k, 1996}^{R, \text { Pres }}+\beta_{T} t_{k, 1996}^{\text {Pres' }} & +\Gamma_{2000} X_{k, 2000} \\
& +\Gamma_{00-90} X_{k, 00-90}+\Gamma_{C} C_{k, 2000}+\varepsilon_{k} .
\end{aligned}
$$

The pre-Fox News political variables from the 1996 presidential elections are the two-party Republican vote share, $v_{k, 1996}^{R \text {,Pres }}$, and the voter turnout measured by log of votes cast as share of population, $t_{k, 1996}^{\text {Pres' }}$. The demographic variables are $X_{k, 2000}$, the

9. The results are similar with logit and conditional logit specifications. 

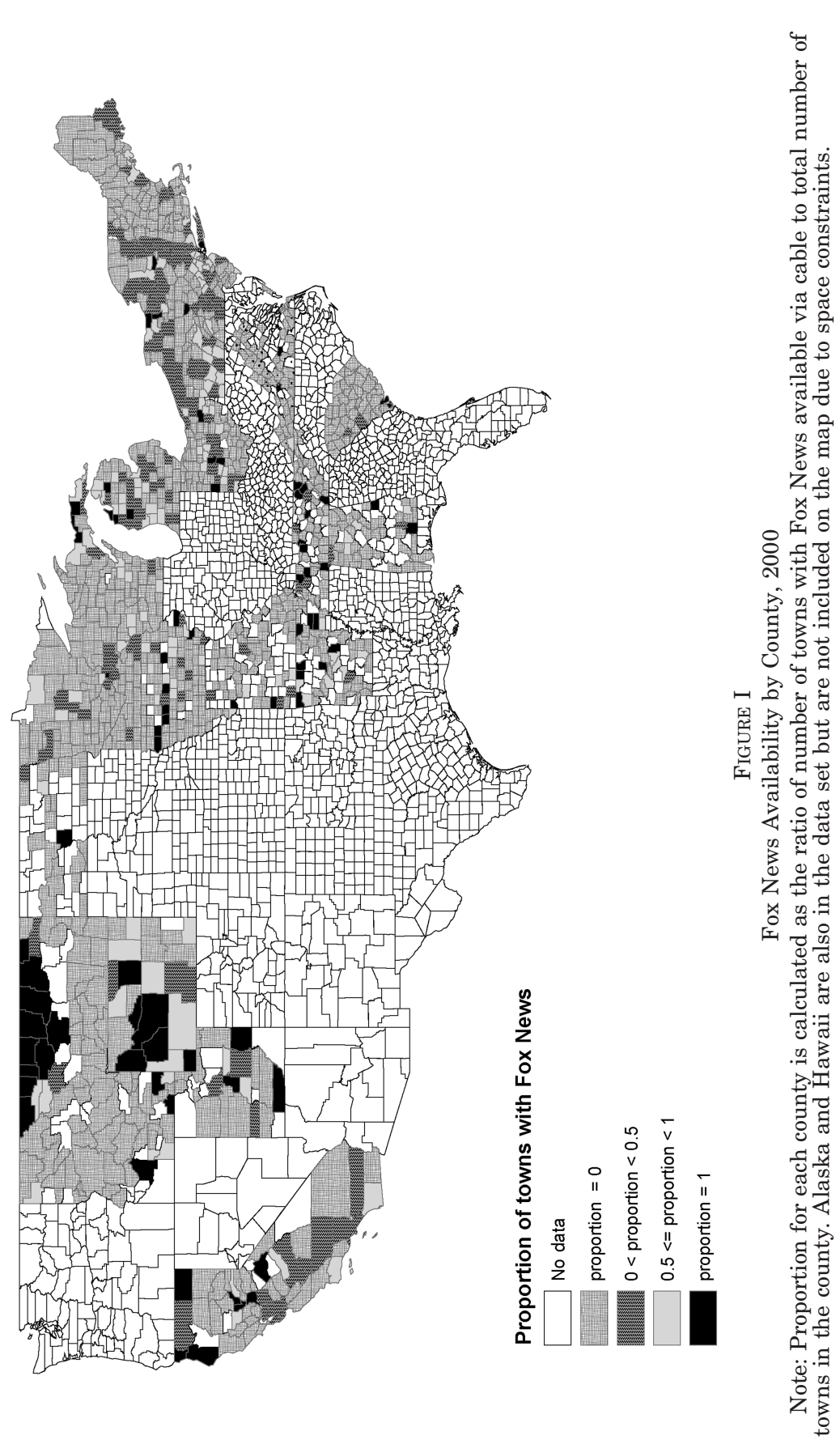
set of controls from the 2000 Census, and $X_{k, 2000-1990}$, the set of changes in controls between the 1990 Census and the 2000 Census (see Table II). Finally, the controls for features of the cable system are $C_{k, 2000}$, deciles in the number of channels provided and in the number of potential subscribers. To ensure that the results are representative of the average voter, and since the

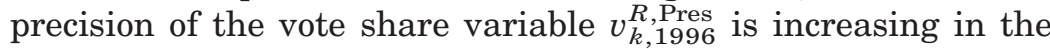
number of votes cast, we weight the observations by votes cast in 1996. ${ }^{10}$ The standard errors are clustered at the level of the 2,992 local cable companies.

We first estimate (1) without controls (column (1) of Table III). Unconditionally, Fox News availability is significantly positively correlated with town turnout, but not with Republican vote share. As we add demographic controls (column (2)), the latter result changes. Fox News availability in 2000 is substantially higher in more Republican towns: a 10 percentage point increase in Republican vote share is associated with a 6.36 percentage point increase in the likelihood of Fox News availability. Since Fox News is more likely to enter into urban towns, and these towns are less likely to be Republican, adding demographics variables in column (2) raises the coefficient on Republican vote share. Next, we add the controls $C_{k, 2000}$ for cable system features (column (3)), raising the $R^{2}$ to 0.4093 ; larger cable systems are much more likely to offer Fox News. Controlling for cable system features lowers the coefficient $\hat{\beta}$ on the Republican vote share by half.

In column (4), we add congressional district fixed effects. With these additional geographic controls, specification (1) captures the determinants of within-district Fox News availability, conditional on demographic and cable controls. (The coefficients on the controls are reported in Appendix II). In this specification, there is no evidence that towns with higher Republican vote share are more likely to offer Fox News; in fact, the estimated $\hat{\beta}=$ -.0343 is negative, albeit insignificant. Similarly, the turnout coefficient is small and insignificant. Given the precision of the estimates, we can reject substantial effects of pre-existing political composition on the availability of Fox News, conditional on the control variables. Moreover, we cannot reject the joint test that the twenty-four demographic controls are zero $(F$-test $=1.11)$. Once we control for geographic heterogeneity and size of the cable

10. The results are similar if we weight by votes cast in 2000 or by population. 


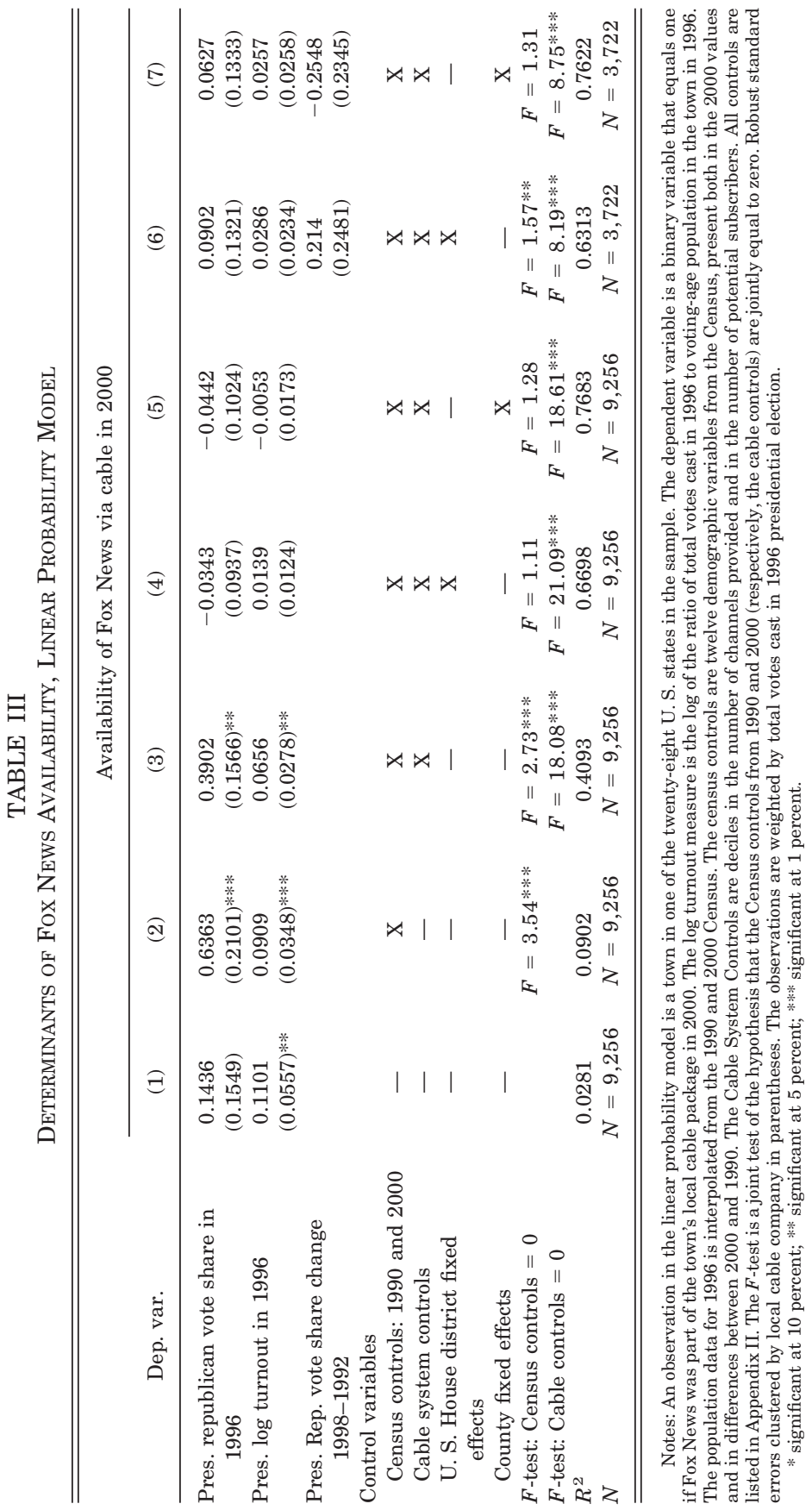


system, availability of Fox News in 2000 is therefore uncorrelated with both political outcomes and demographics. We obtain similar results when we introduce county fixed effects instead of congressional district fixed effects (column (5)). Our interpretation of these results is that, while overall the availability of Fox News is highly selective-Fox News enters into larger markets and, given town size, into more Republican areas-conditional on cable market size, the assignment to towns within an area (county or congressional district) is essentially random.

In columns (6) and (7), we test whether voting trends between 1988 and 1992 predict the availability of Fox News. Since town-level data for 1992 is hard to find, this reduces the sample to 3,722 towns. The vote share change in presidential elections between 1988 and 1992 is not significant and switches sign between the two specifications.

Overall, Fox News in 2000 selected primarily into cable system with a large number of channels, as well as into specific counties and districts. Within counties and districts, however, once we control for features of the cable system, the availability of Fox News in 2000 appears largely idiosyncratic: the towns which got Fox News between 1996 and 2000 are no different in the demographics, the political orientation, or the prior political trends than the towns that did not get Fox News before 2000. We exploit this conditional random assignment to study the impact of Fox News on voting.

\section{III.B. Presidential Elections}

We compare towns where Fox News entered the cable market by the year $2000\left(d_{k, 2000}^{\mathrm{FOX}}=1\right)$ with towns where Fox News was not available by the year $2000\left(d_{k, 2000}^{\mathrm{FOX}}=0\right)$. We consider the impact of the entry of Fox News on the change in the Republican vote share between 1996 and 2000. This strategy exploits the timing of the entry of Fox News. By the November 1996 elections Fox News had been launched in only a few markets and, even in those markets, just one month before the elections. By the November 2000 elections, Fox News had an audience that was smaller, but nonetheless comparable to that of CNN. Our baseline specification is

$$
\begin{aligned}
v_{k, 2000}^{R, \text { Pres }}-v_{k, 1996}^{R, \text { Pres }}=\alpha+\beta_{F} d_{k, 2000}^{\text {FOX }} & +\Gamma_{2000} X_{k, 2000} \\
& +\Gamma_{00-90} X_{k, 00-90}+\Gamma_{C} C_{k, 2000}+\varepsilon_{k} .
\end{aligned}
$$


As in Table III, we control for town-level demographics in levels $\left(X_{k, 2000}\right)$ and changes $\left(X_{k, 00-90}\right)$ and for cable variables $\left(C_{k, 2000}\right)$. The observation are weighted by the votes cast in 1996, and the standard errors are clustered at the level of the local cable company.

We first implement a simple difference-in-difference estimator and estimate (2) without controls $\left(\Gamma_{2000}=\Gamma_{00-90}=0\right.$ and $\Gamma_{C}=$ 0 ) (column (1) in Table IV). On average, in our sample the vote share for Republicans increased by 3.47 percentage points $(\hat{\alpha}=$ 0.0347 ) between the 1996 and the 2000 elections. Compared to this overall increase, towns with Fox News became (insignificantly) less Republican by two-tenths of a percentage point $\left(\hat{\beta}_{F}=\right.$ $-.0025)$ relative to towns without Fox News. The standard error (0.0037), however, is sufficiently large that we cannot rule out that the entry of Fox News increased the Republican vote share by half a percentage point. In column (2), we add demographic controls, raising the $R^{2}$ of the regression from 0.0007 to 0.5207 . The estimate for $\beta_{F}, \hat{\beta}_{F}=0.0027$, becomes positive but is still insignificant. In column (3), we add controls for cable size $C_{k, 2000}$, rendering the Fox News coefficient positive and significant $\left(\hat{\beta}_{F}=\right.$ $0.008)$. Introducing control variables increases the point estimate of $\beta_{F}$, suggesting that the unobservables bias the estimate of the Fox News effect downward.

In the two benchmark specifications we include district fixed effects (column (4)) and county fixed effects (column (5)) in addition to the full set of controls. (The coefficients on the controls for the specification in column (4) are reported in Appendix II.) These specifications control for unobserved trends in voting that are common to a geographic area, and that may be correlated with Fox News availability. The identification of $\beta_{F}$ depends on the comparison of neighboring towns with and without Fox News. The key advantage of specifications with cable, demographic, and geographic controls is that, conditional on these variables, the availability of Fox News is uncorrelated with political variables (Table III). The estimate of the effect of Fox News is positive and significant in both cases, 0.0042 and 0.0069 , respectively. These point estimates are substantially more precise than in column (1). In the specifications that best control for heterogeneity, availability of Fox News increases the Republican vote share by four- to seven-tenths of a percentage point, a sizeable and precisely estimated effect.

In columns (6) and (7), we replicate the benchmark results 


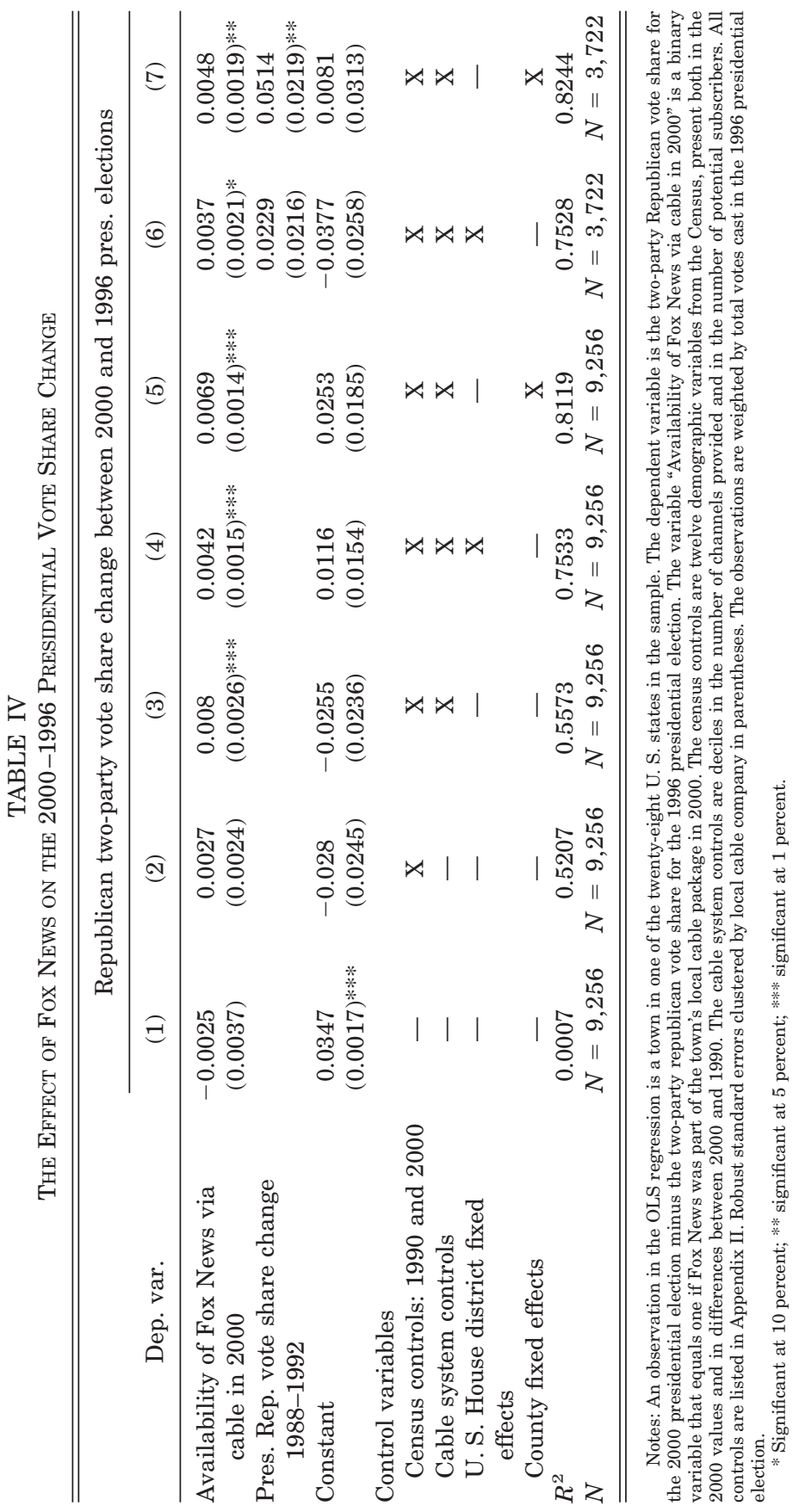


after adding the change in the Republican vote share between 1988 and 1992 as an additional control. Over this substantially smaller sample (3,722 observations), the effect of Fox News availability is less precisely estimated and somewhat smaller but still significant in the specification with county fixed effects. ${ }^{11}$ Since previous voting trends are not substantial predictors of current voting trends, and since including them would lower the sample size substantially, we omit them in the remaining regressions.

Robustness. In Table V, we examine the robustness of the results to alternative ways of coding the dependent variable (the vote share), alternative ways of coding the independent variable (the Fox News indicator), and alternative samples and estimation methods. A more extensive set of robustness checks is in DellaVigna and Kaplan [2006]. Here and in most of the next tables we present the results for the specifications with U.S. House District fixed effects; the results are similar for the specifications with County fixed effects.

First, the results are robust to controlling for the vote share in 1996 instead of using the vote share change between 2000 and 1996 (column (1)). The results are also robust to using the allparty vote share (column (2)), an alternative measure that controls for third-party effects.

Second, we also consider an alternative specification of exposure to Fox News, the ratio of the number of Fox News subscribers to population covered. The results (not shown) are similar to, though less precise than, our main specification, which uses a simple dummy variable.

Third, we present results using alternative samples and estimation methods. In column (3) we show that restricting the sample to the states with a high proportion of correctly matched election data ${ }^{12}$ yields, if anything, a higher effect of Fox News entry. We also show (column (4)) that the largest cities are not driving the estimates: the results are similar to the benchmark results when we run an unweighted regression on medium- and large-sized towns (that is, towns with average turnout in 2000 of

11. The lower point estimates depend on the difference in the sample rather than on the addition of the voting trend controls; we obtain the same result on this sample when we do not control for trends.

12. We exclude states in which the election data in the final sample cover less than 50 percent of the total votes cast in the state in either 1996 or 2000. This eliminates all states in which the town names are obtained from the precinct names, possibly generating erroneous matches with the cable data. 


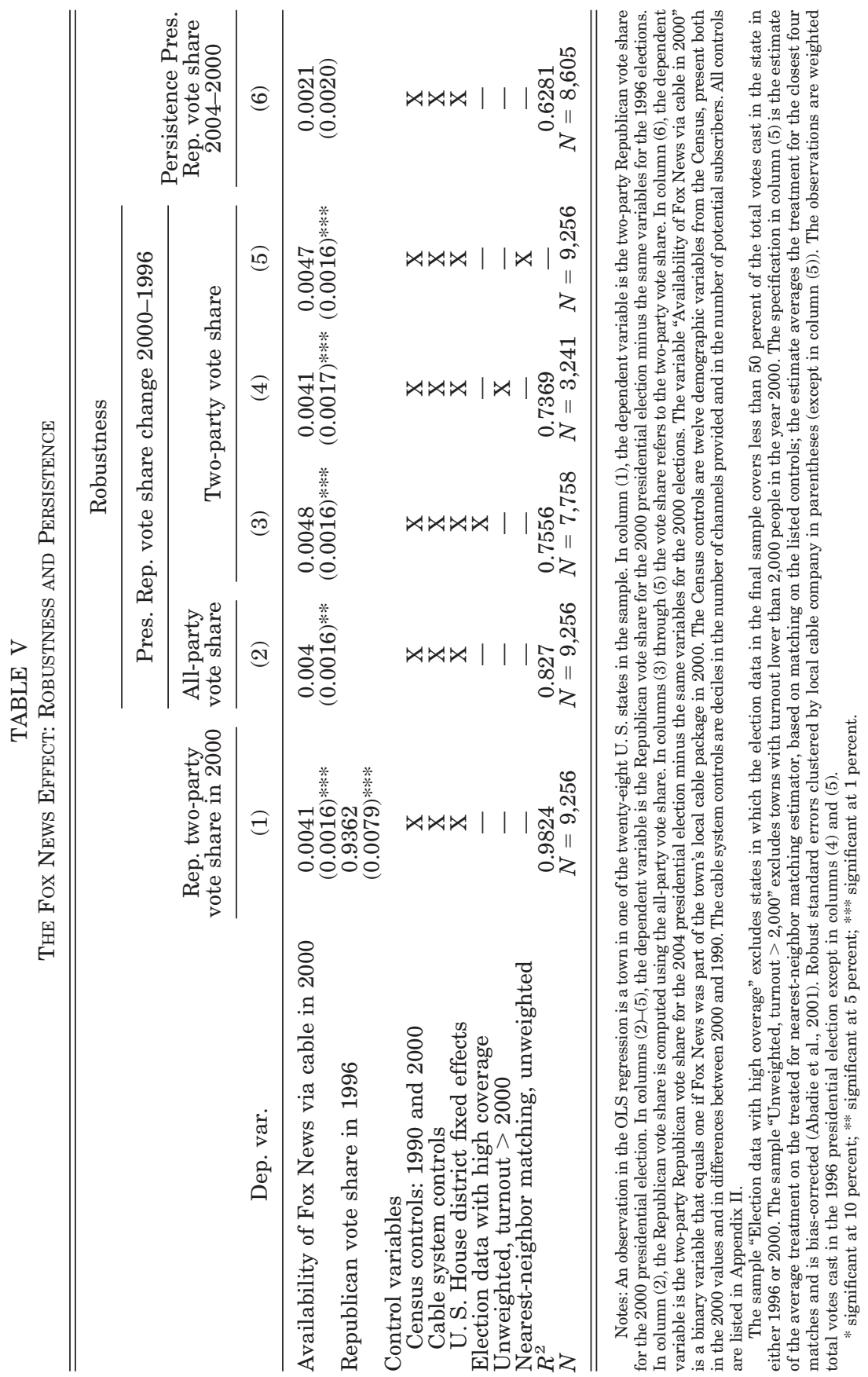


at least 2,000 votes). In Section III.C, we show that the estimated effects are instead smaller in small, mostly rural towns.

To check the robustness of our OLS results, we present the results of a simple matching procedure, nearest-neighbor matching [Abadie et al. 2001]. Each town with Fox News (treatment town) is matched to the four non-Fox News towns (control towns) with the closest values of the controls. The match is based on cable and Census controls and on District indicator variables (column (5)). The (unweighted) average treatment effect of Fox News (0.0047) is significant and similar to our benchmark findings. Finally, the results are also robust to adopting the optimal trimming approach of Crump et al. [2005], which focuses the analysis on an optimal subsample in which treatment and control observations are more comparable (not shown).

Persistence of Effects. We also find that the introduction of Fox News in 2000 is associated with an (insignificant) 0.2 percentage point vote share increase between 2000 and 2004. The effect of Fox News therefore appears to be persistent, if not increasing over time. Persistence is consistent with the predictions of a model of nonrational persuasion; however, this result could also be due to greater audience in Fox News areas over the 2000-2004 period.

Comparison with Earlier Results. We now reconcile the findings with our earlier findings of a null effect of Fox News, as discussed by Krueger [2005]. In an earlier draft, we presented unweighted regressions, we did not drop a group of observations with substantial measurement error, and we used a smaller sample of twenty-four states. In all three respects, we find the current specification preferable. In Appendix III, we introduce in three successive steps the earlier specification and show that, while each of the factors mattered, the first two made the most difference. The estimates of the Fox News effect are 0.3 percentage points lower $(0.0014$ and 0.0040$)$ if we run unweighted regressions (columns (1) and (2)). The effect is still significant with county fixed effects but not with district fixed effects. The lower point estimates are likely due to smaller treatment effects in small, more rural towns (see Section III.C) and possibly to higher measurement error in very small towns. Regressions weighted by turnout better represent the impact of Fox News on the average voter.

In columns (3) and (4), in addition to running unweighted 
regressions, we also include observations that are likely measured with substantial error. We include (as treated) 289 towns where Fox News is offered in parts but not all of the town, and 257 towns with likely voting data problems (see Section II for details). Consistent with increased measurement error in the Fox News variable, the estimates of the Fox News effect are 0.2 percentage points lower. Finally, in columns (5) and (6), we exclude the data from the states of Hawaii, North Dakota, New Jersey, and Wyoming, which we were unable to collect until after our initial results. Excluding these states has only a small impact on the estimates. This last specification, which detects no impact of Fox News, is essentially the one that appeared in the earlier draft.

Magnitudes. Across the different specifications, the entry of Fox News into a cable market by the year 2000 had a significant effect on the Republican vote share in presidential elections. The implied confidence intervals for the benchmark estimates (columns (4) and (5) of Table IV) are $(0.0012,0.0072)$ with district fixed effects and $(0.0041,0.0097)$ with county fixed effects. The findings, therefore, are consistent with both a small (but positive) effect of Fox News and a fairly large effect, close to 1 percentage point.

How large are these effects relative to shifts in vote share between 1996 and 2000? The average weighted change in vote share between 1996 and 2000 in our sample is 3.47 percentage points, with a standard deviation of 4.02. The estimated impact of Fox News is one-tenth of a standard deviation with district fixed effects, and one-sixth of a standard deviation with county fixed effects. The impact of Fox News is small but not negligible.

As a second measure, we estimate the number of votes that Fox News is likely to have shifted. We assume a treatment effect of Fox News of 0.55 percentage points, the midpoint of the benchmark estimates, and a diffusion of Fox News of 34 percent of the population, also for the twenty-two states for which we do not have data. The estimated impact of Fox News on the Republican vote share is then $0.34 *(0.0055)=0.0019$, that is, 0.19 percentage points. Assuming that Fox News did not affect turnout substantially, Fox News shifted approximately 200,000 votes from the Democratic candidate to the Republican candidate.

We also predict the number of votes shifted by Fox News in Florida, the pivotal state in the 2000 U. S. presidential election. 
In 2000, Fox News reached 32.8 percent of the Florida population. We assume that the Fox News effect on the 5,963,110 Florida votes cast is the same as in our sample. Under this assumption, the introduction of Fox News shifted $0.328 *(0.0055) *$ $5,963,110=10,757$ votes, a number substantially larger than Bush's official margin of victory of 537 votes.

Overall, while the entry of Fox News had a relatively small impact on the 2000 election, it may still have contributed to the Bush victory in the unusually close election. Moreover, this impact may become larger over time as the Fox News audience and diffusion grows.

\section{III.C. Interactions}

In Table VI, we examine how the Fox News effect interacts with town characteristics, namely the number of channels, the share of the population that is urban, and the political orientation of the district. We split congressional districts into thirds by the 2000 Republican vote share.

First, we find that the Fox News effect is smaller in towns with more cable channels: an increase of ten cable channels $(0.7$ standard deviations) reduces the effect by 0.19 percentage points with district fixed effects (column (1)) and by 0.13 percentage points with county fixed effects (column (2)). When the Fox News message competes with a larger number of channels, its impact appears diminished [Mullainathan and Shleifer 2005]. The lower Fox News impact could reflect exposure to more balanced reporting (though CNN and the network news are available in all towns in the sample) or merely lower audience rates for Fox News when more channels are available.

Second, we find that the impact of Fox News is (marginally significantly) larger in urban towns and lower in the Republican districts, significantly so with county fixed effects. Both of these results may be explained by the fact that in rural towns and in Republican Districts most people already voted Republican, and therefore, the share of the population at risk of being convinced was smaller. In addition, we also find (not reported) that the Fox News effect is lower in the South, again potentially reflecting a smaller at-risk population.

\section{III.D. Placebos}

We exploit the timing of the Fox News entry to construct placebo treatments. The first placebo treatment (column (3) in 


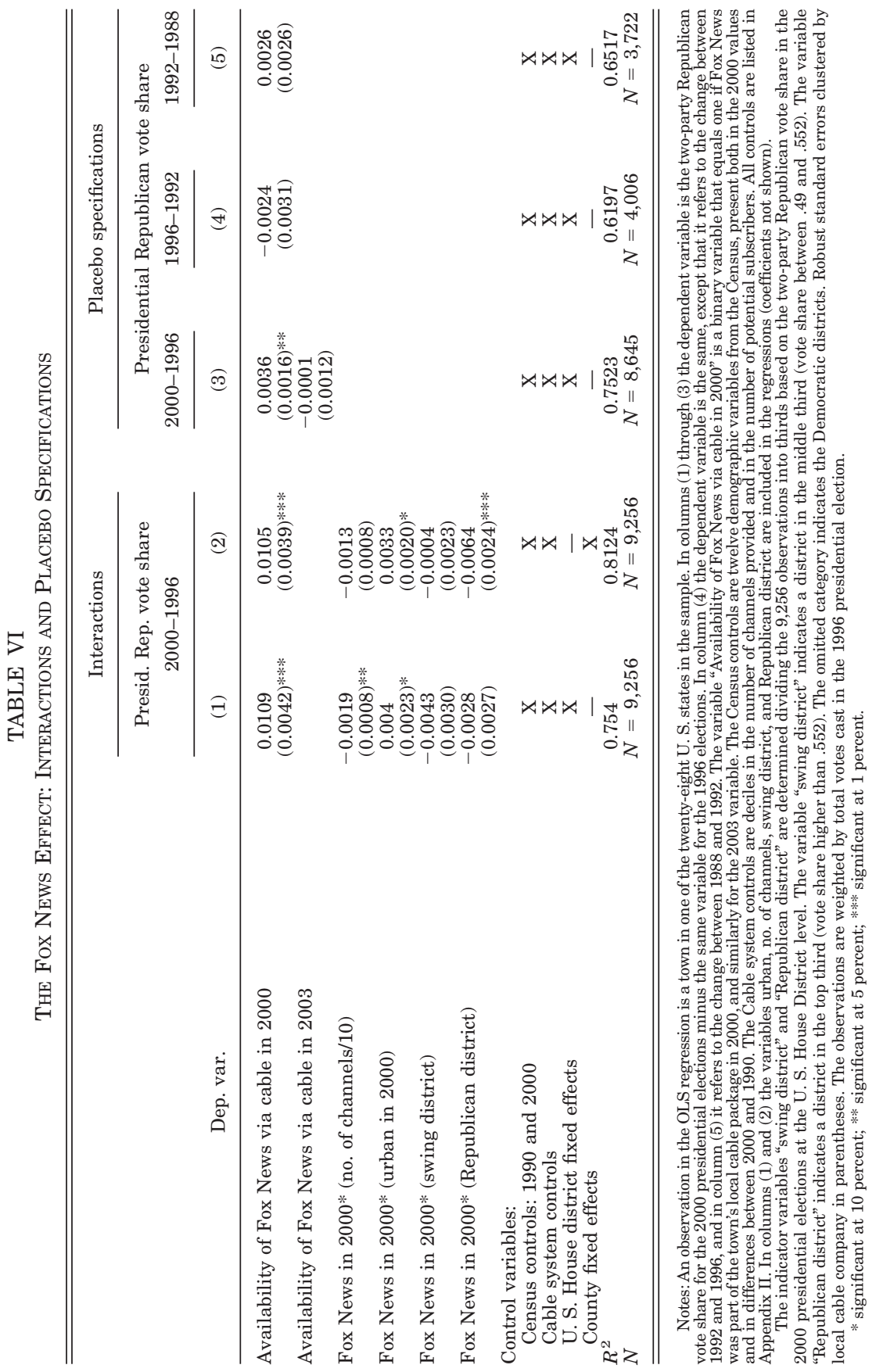


Table VI) uses data on Fox News diffusion in 2003. In 2003, Fox News was available in 4,844 out of 8,645 towns. ${ }^{13}$ The introduction of Fox News after the year 2000 should not affect the change in vote share between 1996 and 2000. Indeed, controlling for Fox News availability in 2000, Fox News availability in 2003 has no effect on voting.

In a second set of placebo treatments, we estimate whether the introduction of Fox News in 2000 predicts the vote share change between 1992 and 1996 (column (4)) or between 1988 and 1992 (column (5)). Obviously, Fox News introduction in 2000 should not affect voting between years in which Fox News did not exist. We find no evidence of a significant correlation in either time period. Voting trends are unlikely to be responsible for the Fox News effect.

\section{III.E. Voter Turnout}

The significant impact of Fox News on the Republican vote share could occur for two reasons. First, Fox News entry convinced Democratic voters to vote Republican. Second, Fox News attracted new Republican voters. We use measures of turnout to test these hypotheses.

The baseline regression for voter turnout is

$$
\begin{aligned}
& t_{k, 2000}^{\mathrm{Pres}}-t_{k, 1996}^{\mathrm{Pres}}=\alpha+\beta_{F} d_{k, 2000}^{\mathrm{FOX}}+\gamma\left[\ln \left(\mathrm{Pop}_{k, 2000}\right)\right. \\
& \left.-\ln \left(\mathrm{Pop}_{k, 1996}\right)\right]+\Gamma_{2000} X_{k, 2000}+\Gamma_{00-90} X_{k, 00-90}+\Gamma_{C} C_{k, 2000}+\varepsilon_{k},
\end{aligned}
$$

where $t_{k, t}^{\text {Pres }}$ is the log total votes in town $k$ in year $t: t_{k, t}^{\text {Pres }}=$ $\ln \left(V_{k, t}^{\mathrm{TOT}, P r e s}\right)$. The change in this measure over time is the percent change in total votes cast. This specification controls for the percentage change in the voting-age town population over time, $\ln \left(\mathrm{Pop}_{k, 2000}\right)-\ln \left(\mathrm{Pop}_{k, 1996}\right)$ since increases in population would naturally increase the number of votes cast.

Columns (1)-(3) in Table VII show the results. The average change in log votes is 0.0869 , implying an 8.69 percent higher turnout in the much tighter presidential race of 2000 . The estimate for $\beta_{F}$ is positive but insignificant with district fixed effects and is large and significant with county fixed effects. This second estimate $\left(\hat{\beta}_{F}=0.0178\right)$ suggests that Fox News increased turnout by 1.78 percent, a large effect. In both specifications, the of the cable systems in the town. The data are updated up to the end of 2003. 


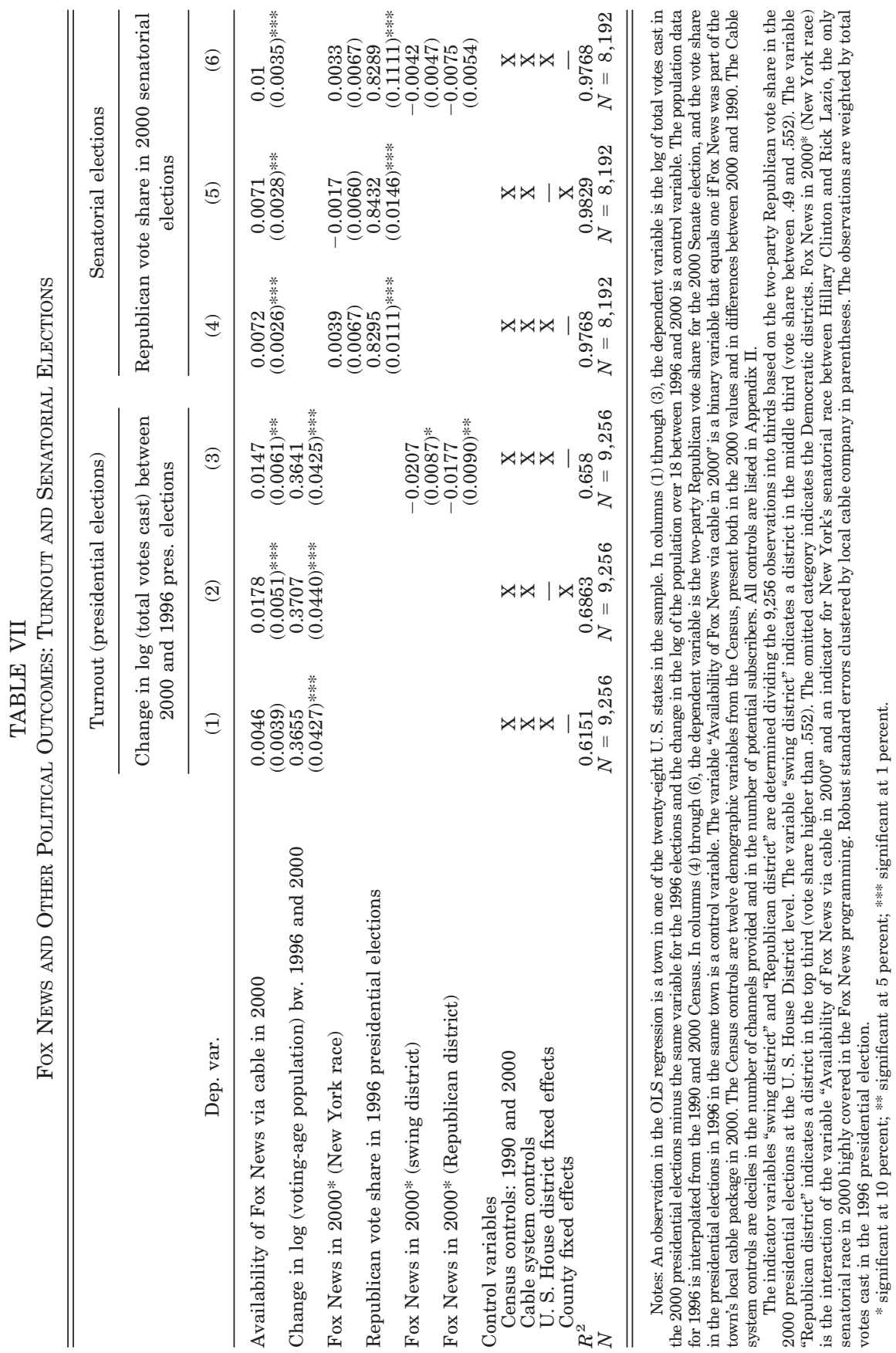


elasticity $\gamma$ of the change in votes cast with respect to the change in population is 0.37 . The turnout effect is concentrated in the more Democratic districts (column (3)). Together with the finding that the impact of Fox News on vote share is larger in the more Democratic areas, this suggests that the main effect of Fox News was to induce nonvoters in Democratic districts to turn out and vote Republican.

Overall, Fox News entry into a market appears to have mobilized new voters, especially in Democratic districts. However, the evidence is not as consistent as for the effect on vote share.

\section{III.F. Senate Elections}

The previous findings suggest that Fox News had a significant effect on the Republican vote share and on turnout in the presidential election. In this section, we consider whether the effect of Fox News extends to local politics not covered by Fox News. This allows us to test whether the Fox News effect is candidate-specific or a general ideological shift.

Senate elections are a good test in this respect because a large majority of Senate races fail to get national coverage. These elections are similar to local elections for which, unfortunately, no town-level data set is available. At the same time, one or two Senate races per year attract substantial national coverage, almost like presidential races. This allows us to compare the effect of Fox News on races that were not covered, where only ideological shifts should matter, to the effect on covered races, where candidate-specific coverage also could matter. In 2000, the Senate race that got the most coverage in Fox News by a wide margin was the Hillary Clinton-Rick Lazio race in New York State. These two candidates had ninety-nine mentions in the O'Reilly Factor and the Hannity \& Colmes show in the two months prior to the 2000 elections, with most mentions critical of Hillary Clinton. ${ }^{14}$ All the other Senate candidates running in the 2000 campaign combined got a total of seventy-three mentions, with Joe Lieberman, who was typically mentioned because of his vicepresidential race, getting the lion's share of these mentions.

We examine whether Fox News impacted the vote share in

14. From the O'Reilly Factor of October 31, 2000: "Mr. Gore does have some honesty issues about campaign finance, but they pale beside the deceit factory the Clintons have set up." 
Senate elections and whether it had a differential effect for the Clinton-Lazio race. We denote by $d_{\mathrm{NY}}$ the indicator variable for the New York Senate races. We estimate the specification

$$
\begin{aligned}
v_{k, 2000}^{R, \text { Sen }}=\alpha+\alpha_{P} v_{k, 1996}^{R, \text { Pres }} & +\beta_{F} d_{k, 2000}^{\mathrm{FOX}}+\phi_{F} d_{k, 2000}^{\mathrm{FOX}} * d_{\mathrm{NY}} \\
& +\Gamma_{2000} X_{k, 2000}+\Gamma_{00-90} X_{k, 00-90}+\Gamma_{C} C_{k, 2000}+\varepsilon_{k},
\end{aligned}
$$

where $\beta_{F}$ indicates the effect of Fox News on Senate races other than New York and $\phi_{F}$ indicates the differential effect for the featured New York race. This specification controls for the 1996 presidential vote share. ${ }^{15}$

Columns (4)-(6) in Table VII report the results. The effect of Fox News on nonfeatured Senate races is large and significant, 0.0072 with district (column (4)) and 0.0071 with county fixed effects (column (5)). Compared to this effect, the impact on the New York race is not significantly different, although the standard errors on the coefficient $\hat{\phi}_{F}$ are relatively large. We then test for heterogeneity by political areas (column (6)). Consistent with the findings for presidential elections, Fox News had the largest impact in Democratic districts.

Fox News affected voting also in nonfeatured Senate races, especially in Democratic districts. We fail to find a stronger effect for highly emphasized races. These results suggest that Fox News exposure induced a generalized ideological shift, as opposed to a candidate-specific effect.

\section{INTERPRETATIONS}

The introduction of a (comparatively speaking) conservative news channel increased the vote share of Republican candidates. We now evaluate the magnitude of this effect by estimating the share of the audience that was convinced by Fox News to vote Republican. We compare this persuasion rate to other media effects in the literature and put forward interpretations.

\section{IV.A. Persuasion Rates}

Model. To compute persuasion rates, we compare treatment towns $T$, where Fox News is available via cable, and control towns $C$, where Fox News is not available via cable. We denote by

15. The results are similar if we control for the 1994 Senatorial vote share instead [see DellaVigna and Kaplan 2006]. The disadvantage of this specification is that it restricts the sample to 2,037 towns in five states. 
$r$ the share of Republican voters and by $d$ the share of Democratic voters, before the introduction of Fox News. For simplicity, we neglect third parties. Consequently, $(1-r-d)$ denotes the share of nonvoters. Since the two types of towns have similar political outcomes in the pre-Fox News period conditional on a set of controls (Tables II and III), we assume that $r$ and $d$ are the same in towns $T$ and $C$.

A fraction $e$ of the town population is exposed to Fox News, after the nationwide introduction. Exposure $e$ is higher in treatment towns; that is, $e_{T}>e_{C} \geq 0$. We allow nonzero exposure $e_{C}$ in control towns because, for example, of the availability of satellite which broadcasts Fox News to subscribers in both towns. For simplicity, we also assume that the exposure $e_{j}$ to Fox News in town $j$ is independent of political affiliation. That is, we assume that Republicans are as likely as Democrats or nonvoters to watch Fox News when available. While Republicans are more likely to watch Fox News (Table I), we cannot rule out that this captures the causal convincing effect of Fox News, rather than differential exposure $e_{j}$ by party.

The key parameter is $f$, the fraction of the audience that is convinced by Fox News to vote Republican. This persuasion rate, $f$, applies equally to Democratic voters and to nonvoters, that is, to a fraction $(1-r)$ of the Fox News audience $e_{j}$, where $j=T, C$. Therefore, the introduction of Fox News increases the fraction voting Republican by $(1-r) e_{j} f$. The two-party vote share $v_{j}$ in town $j$, with $j=T, C$, equals

$$
v_{j}=\frac{r+(1-r) e_{j} f}{r+d+(1-r-d) e_{j} f} .
$$

(Turnout increases since Fox News induces a fraction $f$ of the nonvoters to vote Republican.) Using expression (5), we solve for the difference in vote share between treatment and control towns, $v_{T}-v_{C}$, the equivalent of $\hat{\beta}_{F}$ in the data. We obtain $v_{T}-v_{C}=$ $\left(e_{T}-e_{C}\right) f d / t_{C} t_{T}$, where $t_{j} \equiv\left(r+d+(1-r-d) e_{j} f\right)$ is the turnout in town $j$. The implied persuasion rate $f$ is

$$
f=\frac{v_{T}-v_{C}}{\left(e_{T}-e_{C}\right)(1-r)} \frac{(1-r) t_{C} t_{T}}{d} .
$$

The first term in expression (6) is the influence rate per treated population, and the second term is a factor correcting for turnout effects. The numerator of the first term, $v_{T}-v_{C}$, is the 
shift in Republican vote share due to the availability of Fox News via cable. The denominator, $\left(e_{T}-e_{C}\right)(1-r)$, normalizes this vote shift by the share of population at risk of treatment, that is, by the differential exposure to Fox News, times the share of non-Republicans.

The second term, which disappears if turnout is perfect $(r+$ $d=1$ ), captures the differential convincing effect of Fox News on a Democrat and a nonvoter. In both cases, Republicans gain a vote but only in the first case does the Democratic party lose a vote. The larger the ratio of non-Republicans $(1-r)$ to Democrats $d$, hence, the bigger is the convincing impact for a given vote share change. In addition, the term $t_{C} t_{T}$ corrects for the fact that a higher turnout $t_{j}$ increases the denominator of expression (5), and, therefore, decreases the impact of $f$ on $v_{j}$.

Audience Data. We estimate the differential exposure $\left(e_{T}-\right.$ $e_{C}$ ) in expression (6) using the microlevel Scarborough data on television audiences described in Section II. We use the subsample of 11,388 respondents for whom we observe the zip code of residence and for whom we can match by zip code to the cable data on availability of Fox News (Table I, columns (4)-(6)). We use the "diary audience" measure since the "recall audience" measure is not available for most of this sample. We aggregate the data at the town level to maximize comparability to the specifications in the rest of the paper. For each town $k$ of the 568 towns in this sample, $e_{k}^{\text {FOX }}$ is the fraction of town residents in the Fox News audience. We estimate

$$
\begin{aligned}
e_{k}^{\mathrm{FOX}}=\alpha+\beta_{F} d_{k, 2000}^{\mathrm{FOX}}+\Gamma_{2000} & X_{k, 2000} \\
& +\Gamma_{00-90} X_{k, 00-90}+\Gamma_{C} C_{k, 2000}+\varepsilon_{k} .
\end{aligned}
$$

The regression is weighted by the number of respondents in a town, and the standard errors are clustered at the level of the local cable company. The coefficient $\beta_{F}$ is the differential Fox News diary audience due to Fox News availability via cable in the town.

Table VIII shows the results. In the specification without controls (column (1)), the availability of Fox News induces 2.7 percent $\left(\hat{\beta}_{F}=0.0270\right)$ additional town residents to watch Fox News for at least a full half hour per week. The estimate is significant and sizeable. In towns where Fox News is not available via cable, 2.62 percent $(\hat{\alpha}=0.262)$ of the residents still watch 


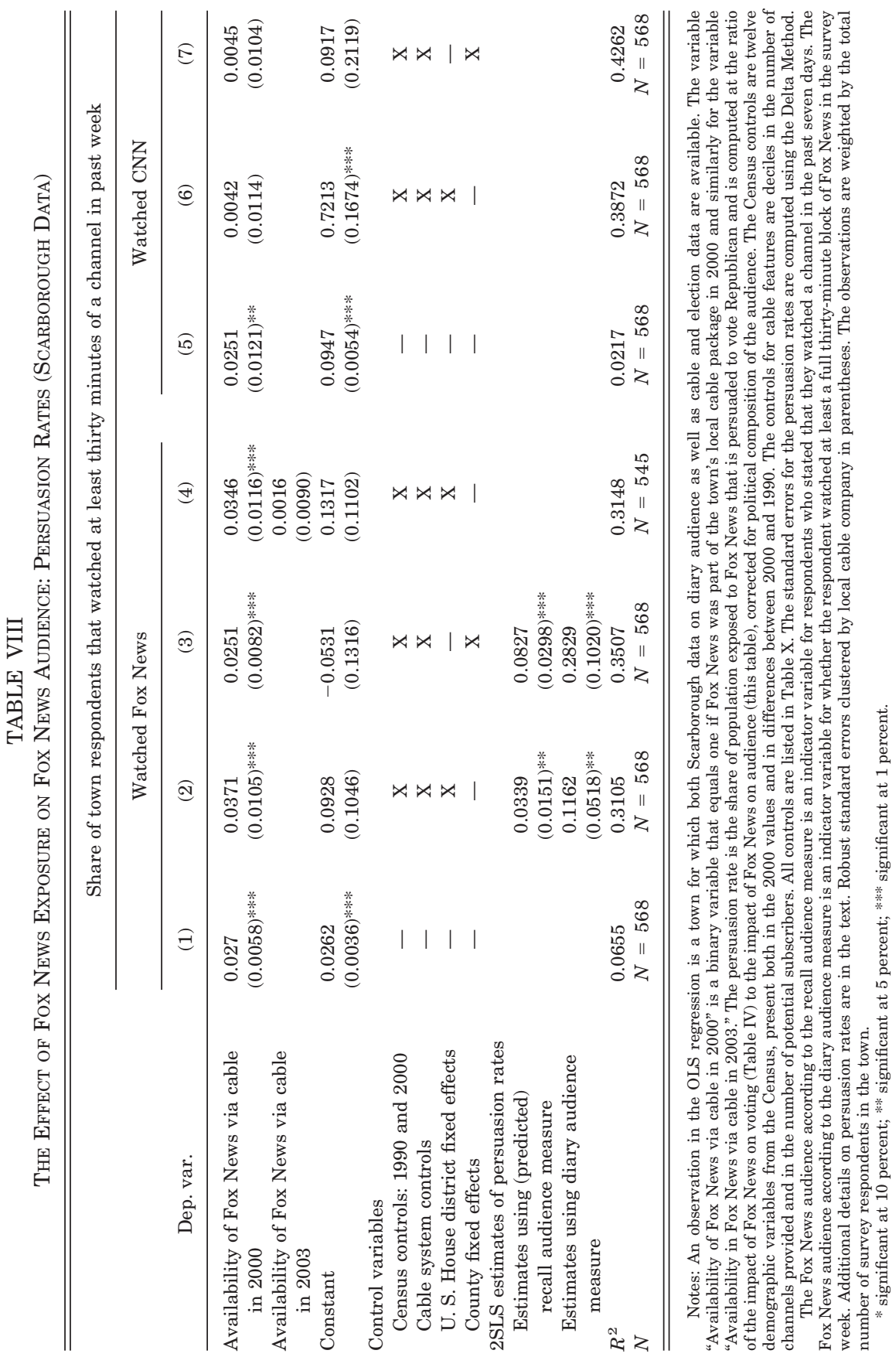


Fox News for at least a full half hour per week. About half of the Fox News audience, therefore, watches Fox News in ways other than via cable, possibly via satellite. This finding could also be due to measurement error in our measure of availability via cable. In either case, the estimates in Section III are likely to understate the impact of Fox News on voting, since they capture only the impact of Fox News availability via cable.

In columns (2) and (3), we add the Census, cable, and geographic controls used in the body of the paper. The estimated differential exposure rates are $\hat{\beta}_{F}=0.0371$ with congressional district fixed effects and $\hat{\beta}_{F}=0.0251$ with county fixed effects. Interestingly, introducing control variables and district fixed effects increases the estimated $\hat{\beta}_{F}$.

As a first placebo test, we show that availability of Fox News via cable in 2003 does not increase audience rates in 2000 (column (4)). As a second placebo test, we show that, once we add controls (columns (6) and (7)) availability of Fox News in 2000 does not increase the audience for CNN (CNN is available in all towns in our sample).

Persuasion Rates. We estimate the persuasion rate $f$ using expression (6). We obtain the differential exposure rate $e_{T}-e_{C}$ as the coefficient $\hat{\beta}_{F}$ of columns (2) and (3) in Table VIII. We first use the more inclusive recall audience measure. Since we cannot directly estimate the model (7) for the recall audience variable, we multiply the estimates of $\hat{\beta}_{F}$ by a conversion rate, the ratio between the aggregate recall audience and diary audience for CNN, that is, $35.3 / 10.3=3.43$ (Table I, column (4)). (The ratio would be somewhat higher if we used the audience measures for Fox News.) The implied estimates for the differential exposure rate $\hat{e}_{T}-\hat{e}_{C}$ are 0.1271 with district fixed effects and 0.0860 with county fixed effects.

We evaluate the political variables $t_{T}, t_{C}, r$, and $d$ using the sample averages of the 2000 elections. We weight the averages by total votes cast in 2000 to better approximate the individual-level expressions (5) and (6). The average weighted turnout in 2000 as a share of the voting-age population is 0.560 , and it is very similar in Fox News and non-Fox News towns, hence $t_{T}=t_{C}=0.560 .{ }^{16}$ The percentage of Democratic voters $d$ is the product of the

16. The average self-reported turnout in the Scarborough survey is 69.3 percent, but self-reported turnout is known to overstate the actual figure. 
turnout rate $t$ and the average weighted Democratic two-party vote share in 2000 in our sample, that is, $0.560 *(1-0.453)=$ 0.306 . This implies that $f=1.024 *\left(v_{T}-v_{C}\right) /\left(e_{T}-e_{C}\right)$.

Combining the estimates of these variables $\left(e_{T}-e_{C}, t_{T}, t_{C}\right.$, $d$ ) with the estimates of the voting impact $\left(v_{T}-v_{C}\right)$ from Table IV, we compute persuasion rates $f$ using the (predicted) recall audience measure. The standard errors for $f$ take into account the uncertainty in both the audience regressions (Table IV) and the vote share regressions (Table VIII) ${ }^{17}$ With congressional district fixed effects we get $f=1.024 *(0.0042 / 0.1271)=0.0339$; that is, Fox News convinced 3.39 percent of its viewers that were not already voting Republican to do so. With county fixed effects, we derive $\hat{f}=1.024 *(0.0069 / 0.0860)=0.0827$; that is, Fox News convinced 8.27 percent of its audience. Both estimates are significantly different from zero, but are fairly imprecisely estimated due to the small sample of the audience regressions.

In Table VIII we also report the persuasion rates $\hat{f}$ computed with respect to the diary audience measure. The persuasion rates are 3.42 times larger if $e_{F}-e_{N}$ is measured using the diary data as the measure of audience. The resulting estimates $\hat{f}=0.1162$ (district fixed effects) and $\hat{f}=0.2829$ (county fixed effects) imply large persuasion effects of the media. We summarize these results in Table VIII and in the first two rows of Table IX.

Robustness. The estimates of the persuasion rate are robust to different estimates of the political parameters. If, instead of using weighted means, we use the unweighted means $(t=0.583$ and $d=0.583 *(1-0.538))$, we obtain $\hat{f}=0.0417$ with district fixed effects and $\hat{f}=0.1012$ with county fixed effects. These effects are in the ballpark of the benchmark estimates.

The persuasion rate estimates are more sensitive to assumptions about the exposure rate. A factor that leads to higher persuasion rates is the self-selection of Republicans in the Fox News audience. In Table VIII, we estimate the selective exposure $e_{T}-$ $e_{C}$ in (7) using the whole population rather than just Democratic voters and nonvoters. To the extent that Republicans self-select

17. The standard errors are computed using the Delta method, taking into account also the covariance between the estimated $\beta_{F}$ in the vote share in the audience regressions (in the sample of towns for which both are available). The standard errors do not take into account the (limited) uncertainty in the estimate of $t_{T}, t_{C}, d$, and of the conversion rate. 
in the Fox News audience, this downward biases the estimate of $f .^{18}$

Conclusion. The estimates using the recall audience imply that Fox News convinced 3 to 8 percent of its audience to shift its voting behavior toward the Republican party, a sizeable media persuasion effect. Alternative estimates using the more restrictive diary audience measure lead to estimates of the persuasion rate between 0.11 and 0.28 , corresponding to large media effects.

\section{IV.B. Persuasion Rates in the Literature}

We estimate persuasion rates $f$ for other studies in the literature summarized in Table IX. We discuss field experiments, laboratory experiments, and surveys.

Field Experiments. In a series of field experiments [Green and Gerber 2004], households within a precinct are randomly selected to receive turn-out-the-vote treatments (canvassing, phone calls, or leaflets) right before an election. Turnout is measured using official individual voting records. In other experiments, the randomization is done at the precinct level, and precinct-level turnout is compared across precincts. Using the same notation as in Section IV.A and denoting by $t$ the turn-out rate, we assume that the treatment convinces a fraction $f$ of the people that do not usually turn out and are exposed, that is, $(1-t) e_{j}$, for $j=T, C$. It follows that $t_{j}=t+f(1-t) e_{j}$ and $t_{T}-t_{C}=(1-$ $t)\left(e_{T}-e_{C}\right) f$. This implies

$$
f=\frac{t_{T}-t_{C}}{e_{T}-e_{C}} \frac{1}{(1-t)} .
$$

In these experiments, $e_{C}=0$ since no one in the control group is treated, hence $t=t_{C}$. In Table IX, we summarize the treatment, election type, year, location, and sample size of five such experiments. Using the turnout rates in the control $\left(t_{C}\right)$ and treatment $\left(t_{T}\right)$ groups and the exposure rate $e_{T}-e_{C}$, we compute the persuasion rate $f$ using expression (8). Canvassing and phone calls convinced between 4 and 26 percent of nonvoters to turn out to the polls.

More recently, Gerber, Karlan, and Bergan [2006] randomly

18. Unfortunately, we cannot restrict the estimation of (7) to non-Republicans, since the party identification variable is measured in 2000 and it captures the causal effect of Fox News, as well as sorting. 


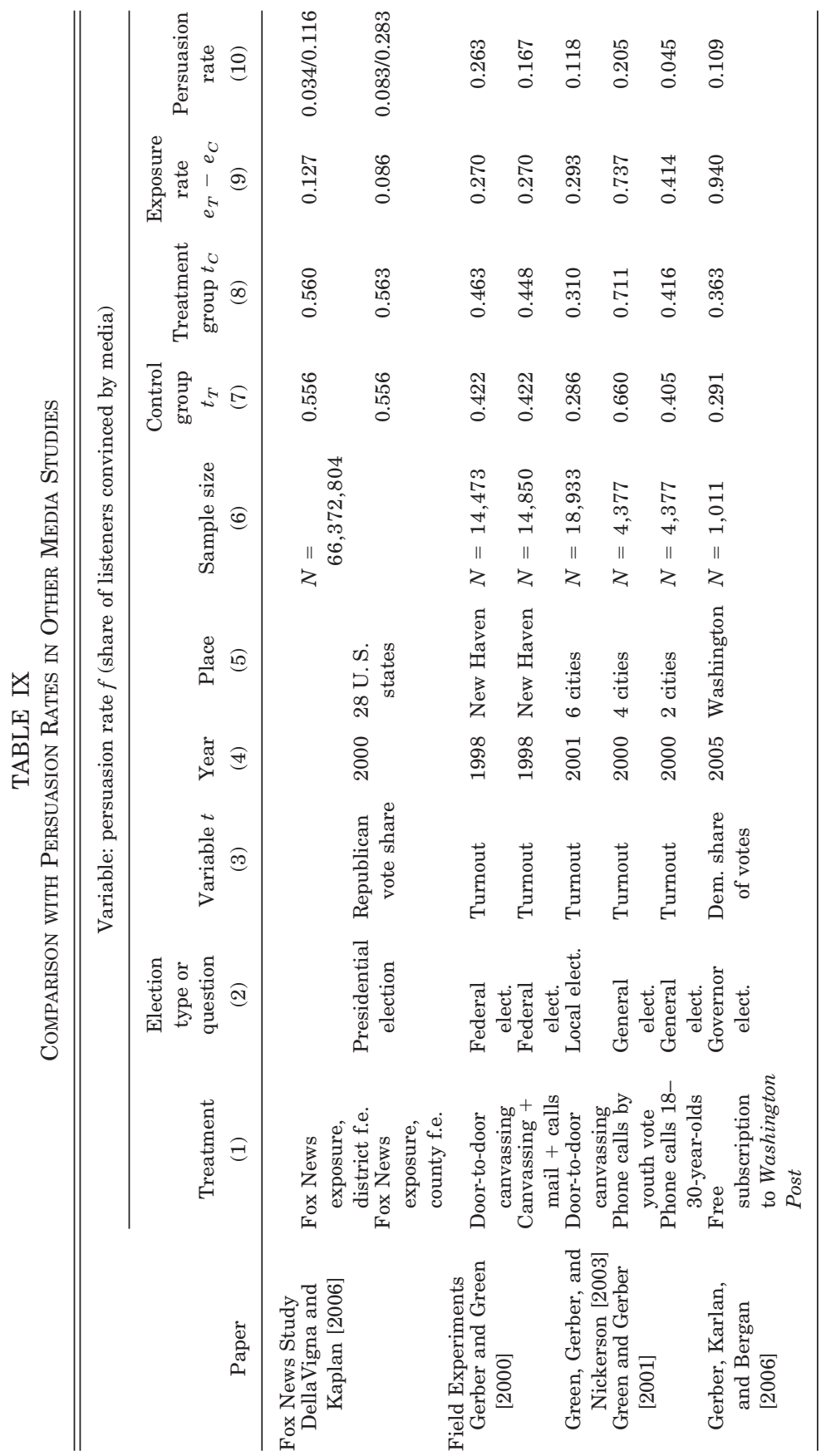




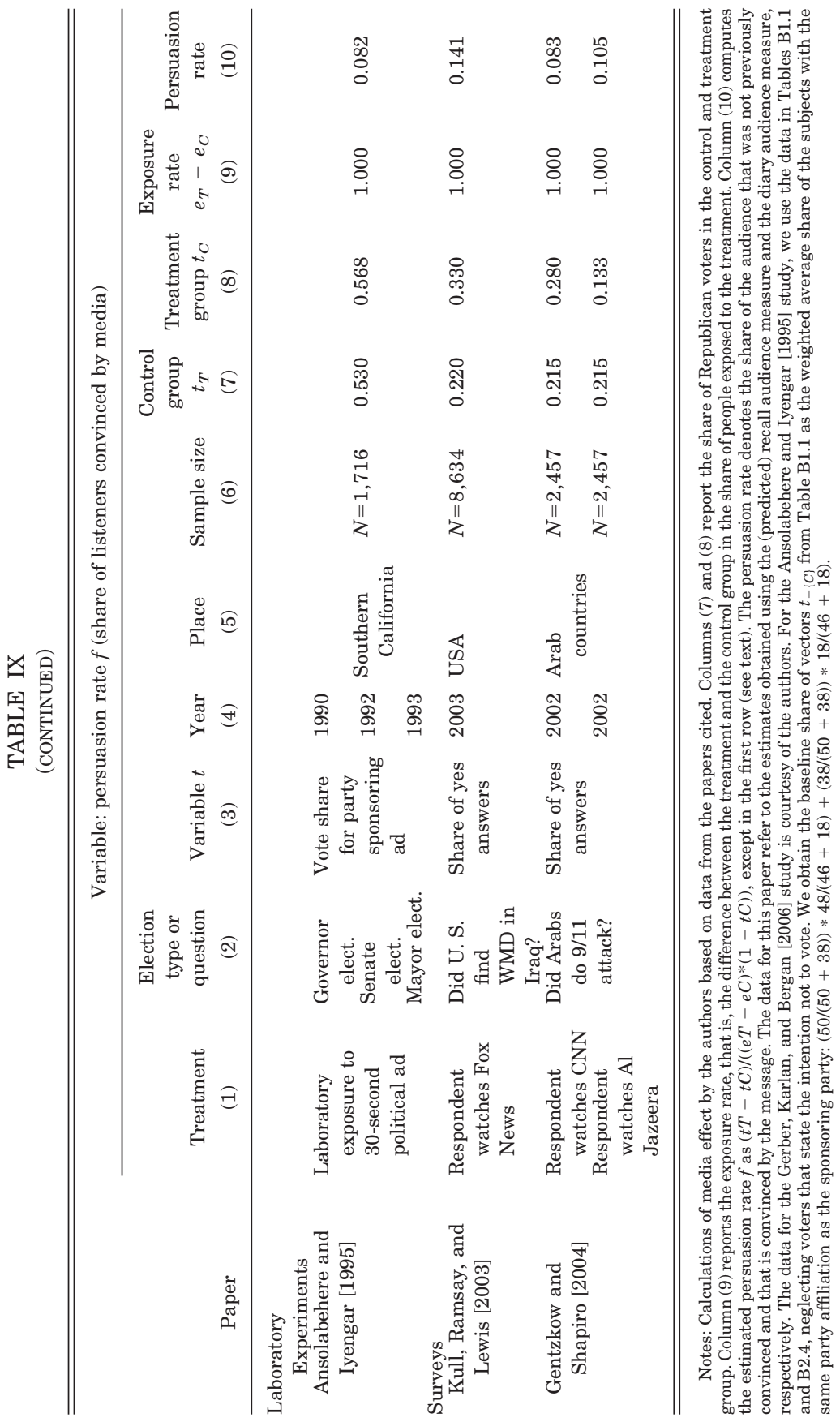


assign subscriptions to a right-wing newspaper (Washington Times) or a left-wing newspaper (Washington Post), and consider the effect on stated voting behavior in a post-election survey. They find a substantial increase in the share of (stated) Democratic voters for exposure to the left-wing newspaper, corresponding to a persuasion rate $f$ of 0.109 . (We use expression (8) where $t$ is the share of Democratic votes out of all survey respondents, including nonvoters, and where we assume that all recipients of a subscription read the newspaper.) However, they also find that the share of Democratic voters increases after exposure to the right-wing paper, albeit insignificantly.

Laboratory Experiments. Ansolabehere and Iyengar (1995] expose experimental subjects to thirty-second political advertisements supporting a candidate (or criticizing the opposite candidate). They then elicit beliefs and voting intentions at the end of the experiment. In Table IX we summarize the findings for three sets of experiments with 1,716 total subjects. On average, exposure to one advertisement yields a sizeable persuasion rate $f$ of 0.08 on the stated vote share for the sponsoring party. Other experiments by the authors (results not reported) lead to persuasion rates of similar or larger magnitudes.

Surveys. Following Lazarsfeld, Berelson, and Gaudet [1944], political scientists have widely used surveys to assess the impact of the media. A survey in this tradition [Kull, Ramsay, and Lewis 2003] finds that 33 percent of Fox News watchers believe (erroneously) that weapons of mass destruction were found in Iraq by October 2003, compared to 22 percent for the overall sample. This implies a persuasion rate $f$ of 0.141 (Table IX). Gentzkow and Shapiro [2004] examine the effect of media exposure in the Islamic world. The CNN audience was 30 percent more likely to believe, and the $\mathrm{Al}$ Jazeera audience was 40 percent less likely to believe that Arabs carried out the 9/11 attacks, compared to respondents who watched neither. The estimates imply persuasion rates between 0.08 and 0.10 . While the survey estimates could be due to sorting rather than causal effects, the implied persuasion rates are quite close to the experimental estimates.

\section{IV.C. Explanations}

Our estimates imply that Fox News convinced a significant portion of its audience to vote Republican. We consider three explanations for this finding: one statistical, one rational, and one 
nonrational. In DellaVigna and Kaplan [2006], we present a model of the last two explanations.

1. Endogeneity Bias. The findings may be spurious and induced by entry of Fox News in towns that were independently becoming more conservative. Contrary to this interpretation, conditional on the controls, vote shares in 1996 and voting trends in 1988-1992 do not predict the introduction of Fox News (Table III). Moreover, the introduction of Fox News does not predict political voting trends between 1992 and 1996 (before the introduction) (Table VII). Fox News only affects vote share changes between 1996 and 2000. Endogeneity of Fox News introduction is unlikely to explain the results.

2. Rational Learning. To the extent that voters are initially uncertain about the bias of Fox News, exposure will have a (temporary) effect on beliefs and voting. Voters attribute the positive coverage of George W. Bush in 2000 partly to Republican bias of the media source (Fox News) but partly also to high quality of the Republican candidate (Bush). A first issue with this interpretation is that, arguably, by the year 2000 the conservative slant of Fox News should have been clear. Second, this explanation makes the prediction that the media effect should disappear over time as voters become aware of Fox News' political slant. Contrary to this prediction, the Fox News effect over the 2000-2004 period gets, if anything, larger (Table V). ${ }^{19}$

3. Nonrational Persuasion. A behavioral interpretation is that viewers do not discount media bias strongly enough [Cain, Loewenstein, and Moore 2005] and therefore are subject to nonrational persuasion upon exposure. This interpretation can explain the persistence of the Fox News effect.

The two most plausible explanations, learning and persuasion, have very different long-run implications. Rational learning predicts that Fox News' impact is temporary. Nonrational persuasion predicts that Fox News permanently altered voting patterns in the United States.

Whether the effect is rational or not, it would be interesting to know the exact mechanism by which Fox News affected voting. The Senate results suggest that the effect is not due only to

19. The increase in the effect over time may also be explained by increasing audience rates. 
candidate-specific coverage, but rather to a general ideological shift. Beyond this, we cannot tell if the effect is due to conservative slant of the news or to the choice of topics like National Security that favor Republicans, as implied by the agenda setting theory [Cohen 1963].

\section{Conclusion}

This paper studies the impact of media bias upon voting. We consider one of the most dramatic changes in the U. S. media in recent years, the sudden introduction and expansion of the Fox News cable channel from 1996 to 2000. We exploit the natural experiment induced by the timing of the entry of the Fox News channel in local cable markets.

We find a significant effect of exposure to Fox News on voting. Towns with Fox News have a 0.4 to 0.7 percentage point higher Republican vote share in the 2000 presidential elections, compared to the 1996 elections. A vote shift of this magnitude is likely to have been decisive in the 2000 elections. We also find an effect on vote share in Senate elections, which Fox News did not cover, suggesting that the Fox News impact extends to general political beliefs. Finally, we find evidence that Fox News increased turnout to the polls.

Based on this evidence and on microlevel audience data, we estimate that exposure to Fox News induced a substantial percentage of the non-Republican viewers to vote for the Republican party, 3 to 8 percent according to the more inclusive audience measure, and 11 to 28 percent according to the more restrictive measure. These estimates are consistent with field, laboratory, and survey evidence of media effects on political beliefs and voting. We interpret the persuasion effect as a temporary learning effect for rational voters or a permanent effect for voters subject to nonrational persuasion. These results suggest that the media can have a sizeable political impact.

This paper leaves a number of open questions. First, while we analyze the extensive margin of voting, we do not consider the effect on the intensity of political convictions of Republican voters. In ongoing research, we study the impact on the intensive margin of campaign contributions. Second, we have not directly examined the impact on policy-making. While a vote shift toward Republicans is likely to induce a change in policy [Lee, Moretti, and Butler 2004], direct evidence documenting this effect would 
be interesting. Finally, we hope that more evidence on the effect of other sources of media bias, such as local papers and radio talk shows, will complement the evidence in this paper.

UC BERKELEY AND NBER

IIES, STOCKHOLM UNIVERSITY

\section{Appendix I: DatA}

\section{A. Cable Data}

The source for the cable data is the Television and Cable Factbook 2001 (referring to year 2000). A typical entry from the Pennsylvania State section is

"KING OF PRUSSIA (Pa)—Comcast Cable. Counties: Delaware and Montgomery. Also serves: Collegeville, Graterford, Graterford Prison, Gulph Mills, [...] Upper Providence Twp. (Delaware County), Wayne. Account No: PA0050. [...]

Basic Service Subscribers 17,692. [. . .] Programming (received off-air): WFMZ-TV (I); WLVT-TV (P) Allentown; WGTW (I) Burlington; KYW-TV (C) [...]. Programming (via satellite): C-SPAN, EWTN; Fox Family Channel; MSNBC [. . .] Fee: [. . .] \$21.95 monthly. [. . .]

Expanded Basic Service Subscribers 17,138. Programming (via satellite): A\&E; AMC; Bravo; CNBC; CNN; Comedy Central; [. . .]. Fee: N.A.

Pay Service 1 Pay units: 845 . Programming (via satellite): Cinemax. Fee: [. . .] \$8.95 monthly. [. . .]

Ownership: Comcast Cable Communications Inc."

Each entry is listed by state under the principal community, which is the town where the local cable company's business office is located. The additional communities reached by the local cable company are listed in alphabetical order, typically without indication of the county, which is listed separately (the number of counties is rarely more than three). In the example above, the communities listed belong to one of two counties (Delaware and Montgomery) in Pennsylvania. Since we do not know which belongs to which, we generate all combinations of town and county, except in cases where the county is explicitly listed as in "Upper Providence Twp. (Delaware County)." When we match the cable data with the Census and election data, the fictitious towncounty combinations drop out. The only possibility of match error is if there are two towns with the same name in the multiple 
counties listed, but in this case we expect the county to be explicitly listed next to the town name. In a few cases, the communities reached are indicated only as fractions of a county, such as "Alameda County (Western borders)." We exclude these communities, since we cannot match them to voting data. As long as these communities do not include other separately listed towns in the cable data, their deletion will not bias the measure of cable offerings for the other towns. As a robustness check, we recompute the results in the paper excluding the 149 counties which include one such community where Fox News is available. All the results hold in this smaller sample of 8,262 towns.

The Basic Service description lists all the local television stations that the cable company rebroadcasts under the heading "Programming (received off-air)." We disregard these stations. We estimate instead the number of cable channels broadcast in the "Programming (via satellite)" section. To save coding time, the total number of channels is estimated counting the number of lines listing cable channels in the Basic and Expanded Basic 1, 2, and 3 Services. The estimated number of channels follows by multiplying this number by 2.5 , a conversion rate estimated on a subsample of forty cable companies. Over this subsample, a regression of actual number of channels on forecasted number of channels yields an $R^{2}$ of 0.95 and a coefficient of 1 .

Finally, it is worth noting that sometimes the number of subscribers or (as in this case) the price of the subscription is missing or refers to previous years.

\section{B. Election Data}

In the aggregation of voting information to the town level, we drop precincts such as "Precinct 1" where the transformation algorithm leads to an empty name. In States like Alabama, Arkansas, and Tennessee, the aggregation procedure generates a very large number of localities because precinct names are often incorrectly identified as a locality by our code. (These fictitious towns drop out from the final sample, since they do not match to Census and cable data.) The New England States, instead, have a small number of exactly identified towns because the election data is reported at the town level.

For the towns that are in multiple districts, we code the town as belonging to the district where the largest fraction of the town's population is represented. 
APPENDIX II: List of Controls for Tables III and IV

\begin{tabular}{|c|c|c|c|c|}
\hline & \multicolumn{2}{|c|}{$\begin{array}{c}\text { Regression of Fox News } \\
\text { on determinants } \\
\text { (Table III) }\end{array}$} & \multicolumn{2}{|c|}{$\begin{array}{c}\text { Regression of vote share } \\
\text { on Fox News } \\
\text { (Table IV) }\end{array}$} \\
\hline & Coefficient & Std. error & Coefficient & Std. error \\
\hline & (1) & (2) & (3) & (4) \\
\hline \multicolumn{5}{|l|}{ Census controls 2000} \\
\hline Population & -0.0004 & $(0.0013)$ & -0.0003 & $(0.0001)^{* * * *}$ \\
\hline High school & 0.0334 & $(0.2233)$ & 0.0252 & $(0.0160)$ \\
\hline Some college & -0.0218 & $(0.1964)$ & -0.0664 & $(0.0141)^{* * *}$ \\
\hline College graduate & 0.0672 & $(0.1599)$ & -0.097 & $(0.0103)^{* * *}$ \\
\hline Male & 0.2285 & $(0.2859)$ & 0.1146 & $(0.0208)^{* * *}$ \\
\hline African American & -0.013 & $(0.1086)$ & -0.0547 & $(0.0061)^{* * * *}$ \\
\hline Hispanic & -0.1155 & $(0.1973)$ & -0.0571 & $(0.0130)^{* * *}$ \\
\hline Employment & 0.0759 & $(0.1225)$ & 0.0367 & $(0.0089)^{* * * *}$ \\
\hline Unemployment & 0.3511 & $(0.3768)$ & 0.1212 & $(0.0265)^{* * *}$ \\
\hline Married & -0.1057 & $(0.1419)$ & 0.0033 & $(0.0078)$ \\
\hline Income & -0.0124 & $(0.0072)^{*}$ & -0.0012 & $(0.0004) * * *$ \\
\hline Urban & -0.0293 & $(0.0251)$ & -0.0073 & $(0.0014) * * *$ \\
\hline \multicolumn{5}{|l|}{ Census controls $2000-1990$} \\
\hline Population & -0.0189 & $(0.0106)^{*}$ & 0.0018 & $(0.0005)^{* * *}$ \\
\hline High school & 0.0132 & $(0.1997)$ & 0.0136 & $(0.0136)$ \\
\hline Some college & -0.1716 & $(0.1931)$ & 0.0596 & $(0.0154)^{* * *}$ \\
\hline College graduate & 0.0351 & $(0.2097)$ & 0.0841 & $(0.0127)^{* * * *}$ \\
\hline Male & -0.218 & $(0.3099)$ & -0.0311 & $(0.0238)$ \\
\hline African American & -0.3921 & $(0.2173)^{*}$ & 0.0687 & $(0.0181)^{* * *}$ \\
\hline Hispanic & -0.0138 & $(0.3556)$ & -0.054 & $(0.0206)^{* * * *}$ \\
\hline Employment & -0.0367 & $(0.1453)$ & -0.0209 & $(0.0109)^{*}$ \\
\hline Unemployment & -0.3466 & $(0.2663)$ & -0.0594 & $(0.0229)^{* * *}$ \\
\hline Married & -0.0786 & $(0.1238)$ & -0.0105 & $(0.0111)$ \\
\hline Income & 0.0157 & $(0.0118)$ & 0.0011 & $(0.0010)$ \\
\hline Urban & -0.0039 & $(0.0280)$ & 0.0029 & $(0.0018)$ \\
\hline \multicolumn{5}{|l|}{ Decile in potential subscribers } \\
\hline Decile 2 & -0.006 & $(0.0188)$ & -0.0007 & $(0.0032)$ \\
\hline Decile 3 & 0.0534 & $(0.0249)^{* *}$ & -0.0006 & $(0.0031)$ \\
\hline Decile 4 & 0.0499 & $(0.0295)^{*}$ & -0.0022 & $(0.0031)$ \\
\hline Decile 5 & 0.0388 & $(0.0334)$ & -0.0053 & $(0.0033)$ \\
\hline Decile 6 & 0.0563 & $(0.0369)$ & -0.006 & $(0.0033)^{*}$ \\
\hline Decile 7 & 0.0259 & $(0.0410)$ & -0.011 & $(0.0034)^{* * *}$ \\
\hline Decile 8 & 0.022 & $(0.0387)$ & -0.0105 & $(0.0035)^{* * *}$ \\
\hline Decile 9 & -0.0056 & $(0.0432)$ & -0.0124 & $(0.0035)^{* * *}$ \\
\hline Decile 10 & 0.1786 & $(0.0481)^{* * * *}$ & -0.0127 & $(0.0035)^{* * *}$ \\
\hline \multicolumn{5}{|l|}{ Decile in number of channels } \\
\hline Decile 2 & 0.0355 & $(0.0221)$ & 0.0024 & $(0.0019)$ \\
\hline Decile 3 & 0.0778 & $(0.0267)^{* * * *}$ & 0.002 & $(0.0021)$ \\
\hline Decile 4 & 0.051 & $(0.0287)^{*}$ & -0.0005 & $(0.0023)$ \\
\hline Decile 5 & 0.0394 & $(0.0344)$ & -0.0011 & $(0.0021)$ \\
\hline Decile 6 & 0.1122 & $(0.0278)^{* * *}$ & 0.0001 & $(0.0019)$ \\
\hline Decile 7 & 0.3347 & $(0.0464)^{* * *}$ & 0.0015 & $(0.0022)$ \\
\hline Decile 8 & 0.4292 & $(0.0526) * * *$ & -0.0017 & $(0.0023)$ \\
\hline Decile 9 & 0.4113 & $(0.0541)^{* * *}$ & -0.0025 & $(0.0023)$ \\
\hline Decile 10 & 0.6475 & $(0.0500)^{* * *}$ & -0.0014 & $(0.0025)$ \\
\hline U. S. House district fixed effects & $\mathrm{X}$ & $\mathrm{X}$ & $\mathrm{X}$ & $\mathrm{X}$ \\
\hline
\end{tabular}

Notes: An observation in the OLS regression is a town. List of controls for the specifications with district fixed effects from Table III (column (4)) and Table IV (column (4)). The number of potential subscribers is the total population covered by a cable system.

*significant at 10 percent; ** significant at 5 percent; ***significant at 1 percent. 


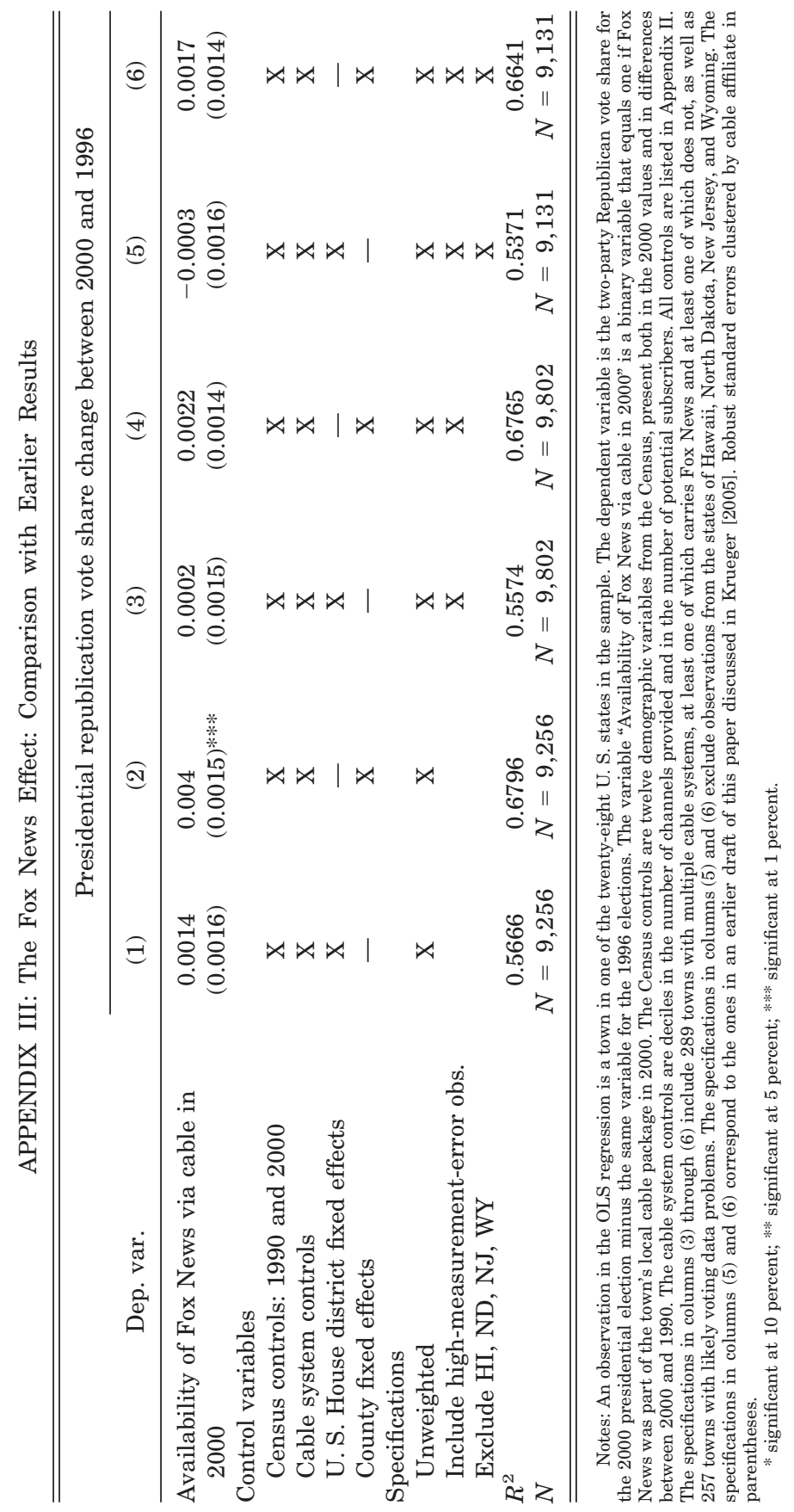




\section{REFERENCES}

Abadie, Alberto, David Drukker, Jane Leber Herr, and Guido Imbens, "Implementing Matching Estimators for Average Treatment Effects in STATA," Stata Journal, I (2001), 1-18.

Ansolabehere, Stephen, and Shanto Iyengar, Going Negative: How Attack Ads Shrinks and Polarize the Electorate (New York: Free Press, 1995).

Bray, Margaret, and David Kreps, "Rational Learning and Rational Expectations," in Arrow and the Ascent of Modern Economic Theory, G. Feiwel, ed. (London: Macmillan, 1987, pp. 597-625).

Cain, Daylain, George Loewenstein, and Don Moore, "The Dirt on Coming Clean: Perverse Effects of Disclosing Conflicts of Interest," Journal of Legal Studies, XXXIV (2005), 1-25.

Cohen, Bernard C., The Press and Foreign Policy (Princeton: Princeton University Press, 1963).

Crump, Richard K., V. Joseph Hotz, Guido W. Imbens, and Oscar Mitnik, "Moving the Goalposts: Addressing Limited Overlap in Estimation of the Average Treatment Effects by Changing the Estimand," Mimeograph, UC Berkeley, 2005.

DellaVigna, Stefano, and Ethan Kaplan, "The Fox News Effect: Media Bias and Voting," NBER Working Paper No. W12169, 2006.

DeMarzo, Peter, Dimitri Vayanos, and Jeffrey Zwiebel, "Persuasion Bias, Social Influence, and Uni-Dimensional Opinions," Quarterly Journal of Economics, CXVIII (2003), 909-968.

Dyck, Alexander, and Luigi Zingales, "The Media and Asset Prices," Working Paper, Harvard Business School, 2003.

Gentzkow, Matthew, "Television and Voter Turnout," Quarterly Journal of Economics, CXXI (2006), 931-972.

_ World," Journal of Economic Perspectives, XVIII (2004), 117-133.

Gentzkow, Matthew, "Media Bias and Reputation," Journal of Political Economy (2006), vol. CXIV, 280-316.

George, Lisa, and Joel Waldfogel, "The New York Times and the Market for Local Newspapers," American Economic Review, XCVI (2006), 435-447.

Gerber, Alan S., and Donald P. Green, "The Effects of Canvassing, Telephone Calls and Direct Mail on Voter Turnout: A Field Experiment," American Political Science Review, XCIV (2000), 653-663.

Gerber, Alan S., Dean Karlan, and Daniel Bergan, "Does The Media Matter? A Field Experiment Measuring the Effect of Newspapers on Voting Behavior and Political Opinions," Mimeograph, Yale University, 2006.

Green, Donald P., and Alan S. Gerber, "Getting Out the Youth Vote: Results from Randomized Field Experiments," Yale University, New Haven, CT, 2001.

— Get Out the Vote! (Washington, D.C.: Brookings Institution Press, 2004).

Green, Donald P, David W. Nickerson, "Getting Out the Vote in Local Elections: Results from Six Door-To-Door Canvassing Experiments," Journal of Politics, LXV (2003), 1083-1096.

Groseclose, Timothy, and Jeff Milyo, "A Measure of Media Bias," Quarterly Journal of Economics, CXX (2005), 1191-1237.

Hamilton, James T., All the News That's Fit to Sell (Princeton: Princeton University Press, 2004).

Herman, Edward, and Noam Chomsky, Manufacturing Consent: The Political Economy of the Mass Media (Pantheon Books, 1998).

Huberman, Gur, and Tomer Regev, "Contagious Speculation and a Cure for Cancer: A Nonevent that Made Stock Prices Soar," Journal of Finance, LVI (2001), 387-396.

King, Gary, Bradley Palmquist, Greg Adams, Micah Altman, Kenneth Benoit, Claudine Gay, Jeffrey B. Lewis, Russ Mayer, and Eric Reinhardt, "The Record of American Democracy, 1984-1990," Harvard University, Cambridge, MA; 1997. ICPSR, Ann Arbor, MI.

Krueger, Alan, "Fair? Balanced? A Study Finds It Does Not Matter," New York Times, August 18, 2005. 
Kull, Steven, Clay Ramsay, and Evan Lewis, "Misperceptions, the Media, and the Iraq War," Political Science Quarterly, CXVIII (2003), 569-598.

Lakoff, George, Women, Fire and Dangerous Things (Chicago, IL: University of Chicago Press, 1987).

Lazarsfeld, Paul, Bernard Berelson, and Hazel Gaudet, The People's Choice (New York: Duell, Sloan and Pearce, 1944).

Lee, David S., Enrico Moretti, and Matthew J. Butler, "Do Voters Affect or Elect Policies? Evidence from the U. S. House," Quarterly Journal of Economics, CXIX (2004), 807-860.

Leip, David, Dave Leip's Atlas of U.S. Presidential Elections (http://www. uselectionatlas.org, 2004).

Lublin, David, and D. Stephen Voss, "Federal Elections Project," American University, Washington, D.C., and the University of Kentucky, Lexington, KY, 2001.

Malmendier, Ulrike, and Devin Shanthikumar, "Are Small Investors Naive about Incentives?" Journal of Financial Economics, forthcoming.

Mullainathan, Sendhil, and Andrei Shleifer, "The Market for News," American Economic Review, XCV (2005), 1031-1053.

Prior, Markus, Post-Broadcast Democracy: How Media Choice Increases Inequality in Political Involvement and Polarizes Elections (Cambridge: Cambridge University Press, 2006).

Puglisi, Riccardo, "Being the New York Times: The Political Behavior of a Newspaper," Mimeograph, 2004.

Stromberg, David, "Radio Impact on Public Spending," Quarterly Journal of Economics, CXIX (2004), 189-221.

Warren, Albert, Television and Cable Factbook 2001 (Washington, DC: Warren Communication News, 2001). 